\title{
LIFE EXPECTANCY, LABOR SUPPLY, AND LONG-RUN GROWTH: RECONCILING THEORY AND EVIDENCE
}

Holger Strulik

Katharina Werner

Georg-August-Universität Göttingen 


\title{
Life Expectancy, Labor Supply, and Long-Run Growth: Reconciling Theory and Evidence
}

\author{
Holger Strulik ${ }^{\dagger}$ \\ Katharina Werner ${ }^{* *}$
}

First Version: March 2012. This Version: September 2012

\begin{abstract}
We set up a simple overlapping generation model that allows us to distinguish between life expectancy and active life expectancy. We show that individuals optimally adjust to a longer active life by educating more and, if the labor supply elasticity is high enough, by supplying less labor. When calibrated to US data the model explains the historical evolution of increasing education and declining labor supply (of cohorts born 1850-1950) as an optimal response to increasing active life expectancy. We integrate the theory into a unified growth model and reestablish increasing life expectancy as an engine of long-run economic development.
\end{abstract}

Keywords: longevity, active life expectancy, education, hours worked, economic growth.

JEL: E20, I25, J22, O10, O40.

\footnotetext{
* This research was funded by the European Commission within the project "Long-Run Economic Perspectives of an Aging Society" (LEPAS) in the Seventh Framework Programme under the Socio-economic Sciences and Humanities theme (Grant Agreement: SSH7-CT-2009-217275). We would like to thank Lothar Banz, Carl-Johan Dalgaard, Caspar Hansen, Pierre Pestieau, and Gregory Ponthiere for useful comments.

${ }^{\dagger}$ University of Goettingen, Department of Economics, Platz der Goettinger Sieben 3, 37073 Goettingen, Germany; email: holger.strulik@wiwi.uni-goettingen.de.

** University of Goettingen, Department of Economics, Platz der Goettinger Sieben 3, 37073 Goettingen, Germany; email: kwerner@uni-goettingen.de.
} 
70 is the new 50.

(William C. Byham, 2007)

\section{INTRODUCTION}

Over the course of human history we observe a strong positive correlation between income and life expectancy as well as between income and education (Preston, 1975, Bils and Klenow, 2000, Krueger and Lindahl, 2001). These aggregates showed no visible trend for millennia and then, in most developed countries, began to rise jointly and permanently roughly at the same time, for example around the year 1800 in England. The observed positive correlation is thus undisputed, constituting basically a stylized fact of successful human development. Yet there exists a lively debate about the interpretation of the correlation.

One popular hypothesis, built upon human capital theory and the life cycle of earnings (Becker, 1962, Ben-Porath, 1967), argues that increasing life expectancy leads to more education and thereby to faster income growth. With contrast to the second link in this chain of causation, which has been debated for quite a while, the first link, the effect of increasing life expectancy on education, was long considered to be self-evident. Recently, however, this link gained scholarly attention as the so called the Ben-Porath mechanism (Hazan, 2009). ${ }^{1}$

In simple words the Ben-Porath mechanism implies that (the expectation of) a longer life leads to more education because it provides a longer working-period during which people can harvest the fruits of their education in form of higher wages. A longer working life makes the opportunity cost of education, stemming from a later entry into the workforce, worthwhile. This line of reasoning seems to suggest that higher education should be associated with more life-time labor supply and, indeed, Hazan (2009) showed, based on a simplified version of the Ben-Porath model, that increasing longevity has a non-negative effect on life-time labor supply. Hazan then continued to show that for male U.S. citizens increasing education was associated with decreasing life-time labor supply since the early 19th century; that is, basically since the onset of modern

1 Economic models arguing in favor of the first link, that is an impact of (adult) longevity on economic growth are, among others, proposed by de la Croix and Licandro (1999), Kalemli-Ozcan, Ryder and Weil (2000), Boucekkine, de la Croix and Licandro (2002, 2003), Zhang et al. (2003), Chakraborty (2004), Soares (2005), Cervellati and Sunde (2005, 2011a), Tamura (2006), and Birchenall (2007). Supportive evidence is provided by Lorentzen et al. (2008) and Cervelatti and Sunde (2011b). A prominent article finding a negative impact of life expectancy on income is Acemoglu et al. (2007). Microeconomic studies generally find a much lower impact of life expectancy on income, see e.g. Weil (2007). A recent review of the literature is Bleakley (2011). Health economists usually argue in favor of reverse causation, running from education to health. A prominent study is Jayachandran and Lleras-Muney (2009); see Cutler et al. (2011) for a recent survey. 
economic growth. Higher life expectancy seemingly cannot have caused education levels to rise through the Ben-Porath mechanism. Consequently, increasing life expectancy - through this channel - could not have caused economic growth.

It is important to note that the evidence does not generally refute increasing longevity as a driving force of education and economic development. It just refutes the simple Ben-Porath mechanism, which in particular ignores a preference for leisure and labor supply at the intensive margin. Hazan is careful in clarifying this point in the concluding remarks of his study (p. 1859): there may exist another theory which can explain how higher life expectancy simultaneously causes less life-time labor supply and more education. The present paper proposes such a theory.

The key idea of our theory is that there exists a distinct period at the end of human life, in which the body is too frail for labor supply to be worthwhile. Basically we re-introduce from the simple life-cycle model the period of old age, conceptualized as a period, in which people can no longer participate in the labor market (for a decent wage) but are lively enough to enjoy utility from consumption. The response of labor supply to increasing life expectancy then crucially depends on which period of the life cycle is expected to get longer. If people expect to stay longer in the inactive and potentially frail state, they work harder during the active period of life. If, in contrast, people expect to stay longer in an active and healthy state, they prefer to reduce labor supply per time increment (i.e. per month or week) in the active period and enjoy more leisure.

With respect to education, increasing longevity has a positive impact no matter where in the life cycle it occurs. Because people derive utility from consumption in every period of their life, a longer life generally induces more education, since higher education provides more income and more utility from consumption per time increment during the active and inactive period. The theory thus predicts unambiguously more eduction and less labor supply per time increment if people expect a longer active period of life. With respect to total labor supply over the life-time the prediction is generally ambiguous because the negative effect of less labor supply on the intensive margin could be offset by a longer active life. In the paper we show that the negative effect dominates if the labor supply elasticity is sufficiently large. In that case the theory predicts that increasing life expectancy causes more education and less life-time labor supply.

We calibrate the model with data for male US citizens and show that the life cycle model explains the historical evolution of life expectancy, education, and labor supply as presented in 
Hazan's (2009) study quite well. We then develop a unified growth model in which education is the driving force of technological progress as, for example, in Galor and Weil (2000), Galor (2005, 2011), and Cervellati and Sunde (2005), and show that the life cycle model explains the historical evolution of TFP growth and GDP growth quite well. Finally we consider an alternative calibration with data for an average (unisex) US American citizen provided by Ramey and Francis (2009) and show that our model - albeit with a much lower labor supply elasticity provides also a reasonable fit of the historical trajectories suggested in that study. The fact that education and labor supply, in theory as well as in any application, are driven by increasing life expectancy re-establishes this channel as an important driver of long-run economic development.

The theory thus suggests a compromise between studies arguing in favor of life-expectancy as a driving force of economic development (as, for example, Cervellati and Sunde, 2005) versus studies emphasizing health or morbidity (as, for example, Hazan and Zoabi, 2006). Here, we argue that it is the interaction between healthy and unhealthy years of life that can take account for the historical evolution of labor supply and education.

In the medical and gerontological literature we find ample evidence for a distinct third period of life. For example, in the year 2000 in the US $27 \%$ of the non-institutionalized elderly population reported fair or poor health and 35\% reported limitations of activity due to chronic diseases (Rice and Fineman, 2004). With contrast to economic life cycle models, in which aging is mostly conceptualized as the passing of life-time, biologists define aging as the intrinsic, cumulative, progressive, and deleterious loss of function that eventually culminates in death (Arking, 2006). The work by Mitnitski and coauthors $(2002,2005,2006)$ documents impressively how human frailty, on average, increases with age. At the individual level, however, the aging process exhibits great plasticity and is only imperfectly captured by chronological age; some 60 year-olds are as fit as some 40 year-olds and vice versa. Chronological age, that is distance from birth, is thus a poor measure of frailty, which is better approximated by distance from death.

Over the last century, the state of health of the elderly improved substantially. Members of later born cohorts can not only expect to live longer but also to live longer in a healthy state. These gains are measured by healthy life expectancy, sometimes also called active life expectancy, defined by the average number of years that a person can expect to live in "full health", that is without disability or injury (WHO, 2012). Manton et al. (2006) estimate that for 65 year old US 
citizens the ratio between healthy (active) life expectancy and life expectancy rose from $73.9 \%$ in 1935 to $78.5 \%$ in 1999 and predict the ratio to increase further to $88 \%$ in the year 2080 .

From a gerontological viewpoint it still remains a dream of the future that "70 is the new 50" (Byham, 2007). Nevertheless, in developed countries, older people have already experienced substantial gains in "good" years of life. Baltes and Smith (2003) conclude that the state of health of today's 70 year-old US Americans is comparable to the one of 65 year olds who lived 30 years ago. Naturally, these improvements are not the consequence of genetic mutations but man-made or "manufactured" (Carnes and Olshansky, 1997) and largely driven by education through increasing knowledge about healthy behavior and medical technological progress (Rice and Fineman, 2004, Manton et al., 2006, Skirbekk et al., 2012).

The left hand side of Figure 1 shows that life expectancy and healthy life expectancy are strongly correlated across countries. As life expectancy improves, healthy life expectancy improves "in sync". But what looks like a linear correlation to the naked eye is actually mildly non-linear. This fact is revealed in the right panel of Figure 1. As life expectancy increases, the share of healthy years increases as well, by about 0.35 percent for every year of life expectancy. With improving longevity we get more healthy as well as more unhealthy years but we get a bit more healthy than unhealthy years. That is, healthy or active life expectancy improves relatively to longevity. This is the stylized fact upon which we built our theory. ${ }^{2}$

A related but different proposal to square Hazan's observation with economic rationality has been made by Cervelatti and Sunde (2010, see also Sheshinski, 2009). They show that Hazan's argument rests on the assumption of a rectangular survival curve. Taking age dependent mortality into account, expected years in the workforce are actually increasing and, given a relatively low labor supply of young adults, it can well be that marginal benefits of education exceed marginal costs. Their mechanism, in contrast to ours, is based on survival during working age and, as the authors emphasize, it is independent from retirement age (i.e. length of active life) and longevity (life expectancy). It complements "our" mechanism, which is built on increasing active life length. Cervelatti and Sunde have not yet implemented their refined view on life expectancy in their own macro work. Our study, with contrast, integrates the active-life mechanism into a

2 Ideally, to corroborate our theory we would need data on the evolution of healthy life expectancy within countries. Given that the idea of healthy life expectancy is relatively new, there is, unfortunately, not sufficiently many data available for time series analysis. 
Figure 1: Life Expectancy vs. Healthy Life Expectancy Across Countries
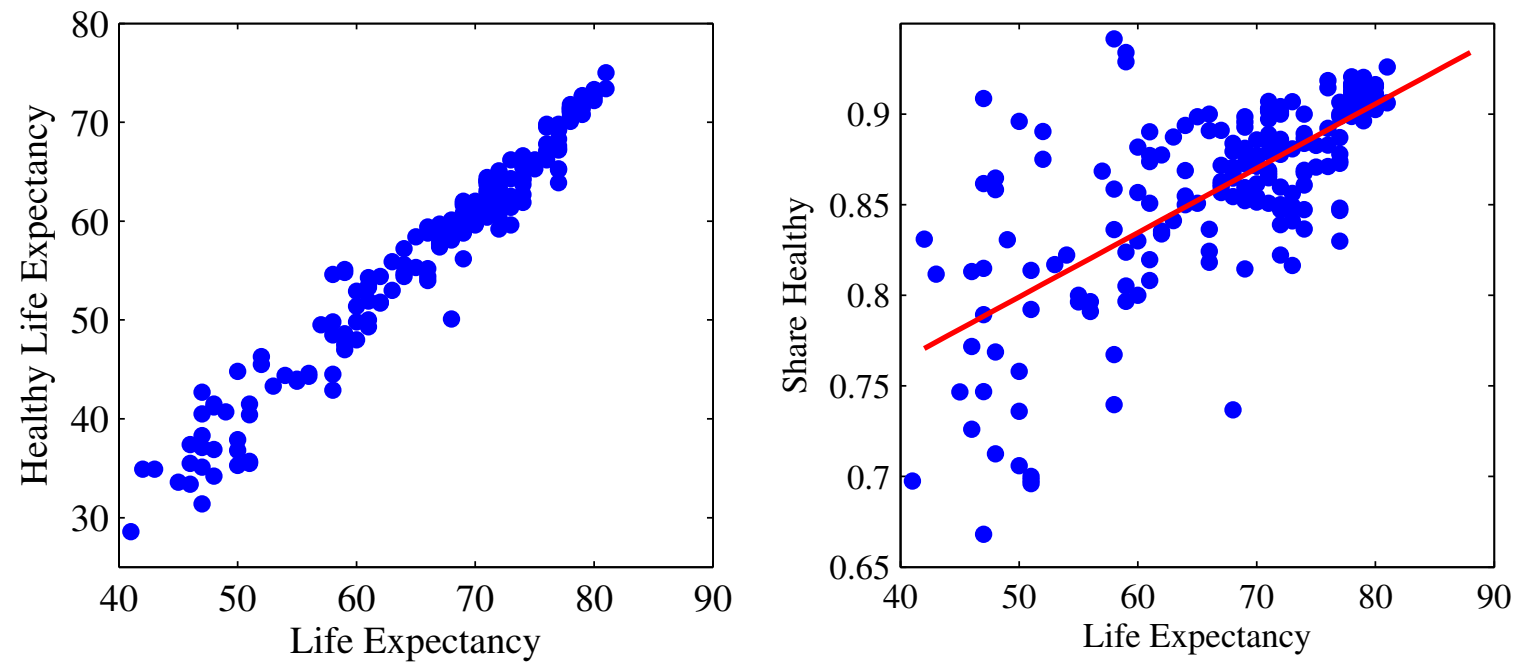

Data for 191 countries from WHO (2012). Life expectancy at 5 from year 2000, healthy life expectancy at 5 from year 2002. Share Healthy (SH) is healthy life expectancy divided by life expectancy (LE). Regression line: $\mathrm{SH}=0.61+0.0035 \mathrm{LE} ; 95 \%$ confidence interval for coefficient: [0.0030, 0.0041].

unified growth model and shows how increasing life expectancy explains the onset and gradual increase of economic growth as well as the observed decline of labor supply.

Recently, d'Albis et al. (2012) have shown in a continuous time life-cycle model that individuals retire later if mortality declines in old age and earlier if mortality declines at younger ages. However, d'Albis et al. (2012) do neither consider educational choice nor labor supply at the intensive margin. They do also not investigate the quantitative power of their model and abstain from integrating it into a unified growth context.

Finally, Hansen and Loenstrup (2012) propose an alternative channel through which increasing life expectancy may have reverse effects on labor supply and education. It relies on missing capital markets for young people and, like Kalemli-Ozcan and Weil (2010), on uncertainty and missing annuity markets for old people. The mechanism goes as follows. A higher probability to enter old age reduces accidental bequests (which are taxed away by the government), a fact that induces middle-aged people to save more. Consumption smoothing individuals, however, prefer to distribute more savings and thus lower consumption on both periods, youth and middle age. With missing capital markets in youth this can only be achieved by spending more time on education. In contrast, our mechanism is built upon the notion of active life expectancy and not on missing markets for annuities or credit. Nevertheless we neglect credit financed consumption 
in youth in order to simplify the analysis and to avoid distraction from the main point by adding yet another choice problem and another market.

\section{The Model}

2.1. Demographic Structure. Consider an economy populated by several overlapping generations. At any given time each generation experiences one of three distinct periods of the life cycle:

- youth: a period, in which young individuals decide how to allocate their time on working and schooling.

- (healthy) middle age: a period, in which educated individuals decide how to allocate their time on working and leisure and how to allocate their labor income on consumption and savings for old age.

- (frail) old age: a period, in which health and productivity of individuals has deteriorated to such a degree that their labor is no longer in demand.

In order to focus the analysis on the impact of adult longevity we abstract from endogenous fertility and infant mortality. The first period of life is of length $\tau_{0}$. Later on, in the calibration, we associate this length with 20 years. The duration of the second and third period of life is given for any generation but changes over the course of human history. We denote the expected length of life in middle age by $\tau_{1}>\tau_{0}$ and call the term $\Lambda \equiv \tau_{0}+\tau_{1}$ active life expectancy. Likewise we denote the expected time spent in old age and frailty by $\tau_{2}>0$ such that $L E \equiv \tau_{0}+\tau_{1}+\tau_{2}$ is (total) life expectancy. Since $\partial \Lambda / \partial \tau_{1}=1$ we say that an increase in $\tau_{1}$ is an increase in active life expectancy.

In order to allow for an algebraic discussion and yet get a fine-tuned calibration later on we assume that time is subdivided into arbitrarily small time increments, denoted by $t$, (later on this will be calibrated as years) but that only every $\tau_{0}$ time increments a new generation enters life at the beginning of the education period. This renders a simple three-period OLG model, in which the life-time spent in middle age and old age is variable. The three periods of life are illustrated in Figure 2. The figure is drawn to capture the fact that middle age is naturally the longest period in life. The stylized facts from the Introduction could be illustrated in Figure 2 by the fact that $\tau_{1}$ and $\tau_{2}$ expand with economic development whereby $\tau_{1}$ gets relatively larger. In the medical literature this phenomenon is known as compression of morbidity (Fries, 1980). 
Figure 2: Demography

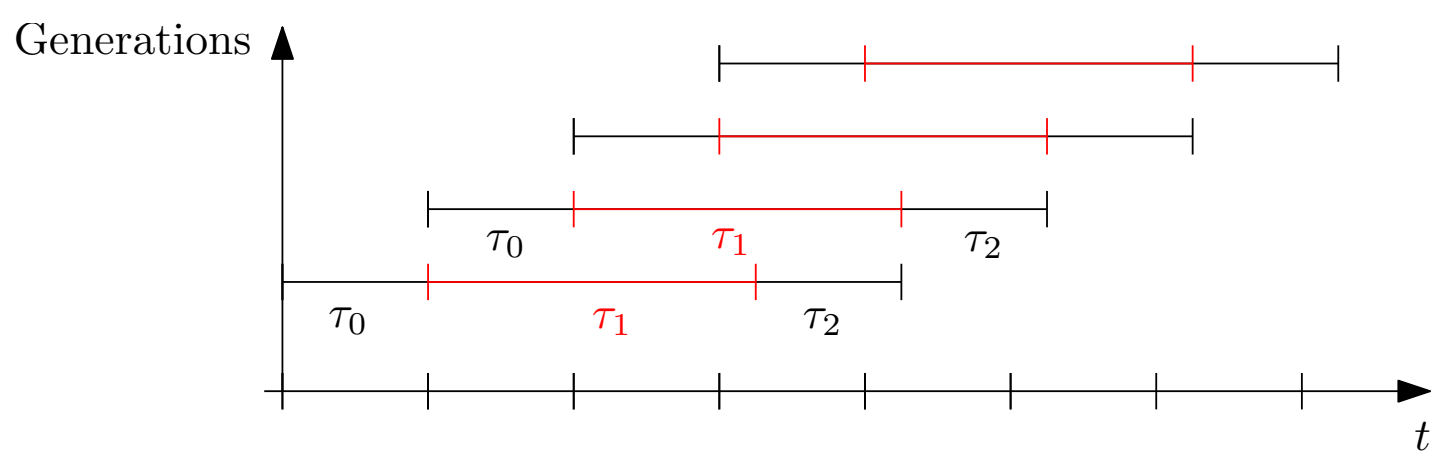

Without implications for our qualitative results we could have added an element of uncertainty by imposing transition probabilities from one period of life to the next. For simplicity, we neglected uncertainty issues such that people correctly anticipate the length of their (active) life. Note that our definition of active life expectancy deviates mildly from the use of the word in gerontology where it is defined as years of life in a non-disabled state, that is, as synonymous with healthy life expectancy. Here, active life expectancy defines the years of potential participation in the workforce. At the end of their active life, individuals can no longer participate in the workforce because their productivity (in a learned occupation) has deteriorated too much. This does not preclude an "active" life outside the workforce in leisurely activities. Furthermore, we allow individuals to withdraw gradually from the workforce with increasing age before the end of the period of middle age.

2.2. The Decision Problem. In all three periods of life individuals gain utility from consumption. In each time increment of the first period they divide their time between education $\bar{\epsilon}_{t, \tau_{0}}$ and work $1-\bar{\epsilon}_{t, \tau_{0}}$, where $\bar{\epsilon}_{t, \tau_{0}} \in[0,1)$ denotes the average education per time increment of an individual born in $t$ over the $\tau_{0}$ time increments of his youth. Let $\bar{w}_{t, \tau_{0}}$ be the average wage per unit of human capital. Initial human capital is normalized to unity and through education young people acquire human capital $h\left(\bar{\epsilon}_{t, \tau_{0}}\right) \geq 1, h^{\prime}>0, h^{\prime \prime}>0$. For simplicity and without loss of generality we ignore credit financed consumption as well as savings during the first period. Average income per time increment of the young is then given by $\left(1-\bar{\epsilon}_{t, \tau_{0}}\right) \bar{w}_{t, \tau_{0}}$ and average consumption $\bar{c}_{t, \tau_{0}}$ is given by

$$
\bar{c}_{t, \tau_{0}}=\left(1-\bar{\epsilon}_{t, \tau_{0}}\right) \bar{w}_{t, \tau_{0}}
$$


In the second period individuals divide their time between work $\bar{l}_{t+1, \tau_{1}} \in(0,1]$ and leisure. To discuss labor supply properly it is useful to conceptualize the period of length $\tau_{1}$ (for example, 50 years) as divided into time increments (for example, months). At each time increment the individual supplies $\bar{l}_{t+1, \tau_{1}}$ units of labor and earns an income $\bar{l}_{t+1, \tau_{1}} h\left(\bar{\epsilon}_{t, \tau_{0}}\right) \bar{w}_{t+1, \tau_{1}}$. Here $\bar{l}_{t+1, \tau_{1}}$ denotes the average labor supply per time increment over the period length $\tau_{1}$ of an individual who enters the middle aged period at time $t+1$ (average consumption consumption $\bar{c}_{t+1, \tau_{1}}$ and the wages $\bar{w}_{t+1, \tau_{1}}$ are analogously defined). During the period individuals spend their income on consumption $\bar{c}_{t+1, \tau_{1}}$ and saving for old age $\bar{s}_{t+1, \tau_{1}}$. The period budget constraint is thus given by

$$
\tau_{1} \bar{c}_{t+1, \tau_{1}}+\tau_{1} \bar{s}_{t+1, \tau_{1}}=\tau_{1} \bar{l}_{t+1, \tau_{1}} h\left(\bar{\epsilon}_{t, \tau_{0}}\right) \bar{w}_{t+1, \tau_{1}} .
$$

In the third period, retired individuals consume the returns on their savings. Let $\bar{R}_{t+1, \tau_{1}} \equiv$ $1+\bar{r}_{t+1, \tau_{1}}$ denote the average gross interest rate over the $\tau_{1}$ time increments of the working life of the individual and let $\bar{c}_{t+2, \tau_{2}}$ denote average consumption in old age. The period budget constraint is then obtained as

$$
\tau_{2} \bar{c}_{t+2, \tau_{2}}=\bar{s}_{t+1, \tau_{1}} \cdot \sum_{j=1}^{\tau_{1}} \bar{R}_{t+1, \tau_{1}}^{j}=\bar{s}_{t+1, \tau_{1}} \cdot \frac{1-\bar{R}_{t+1, \tau_{1}}^{\tau_{1}}}{1-\bar{R}_{t+1, \tau_{1}}}=: \bar{s}_{t+1, \tau_{1}} \widetilde{R}_{t+1, \tau_{1}}
$$

A longer working life, keeping saving per time increment constant, leads to more savings available in old age. Keeping total savings constant, a longer retirement age (i.e. a higher $\tau_{2}$ ) results in less consumption per time increment.

Individuals maximize expected life-time utility. Assuming intertemporal separability, this problem reads

$$
\max U=\tau_{0} u\left(\bar{c}_{t, \tau_{0}}\right)+\tau_{1} \beta\left[u\left(\bar{c}_{t+1, \tau_{1}}\right)-v\left(a, \bar{l}_{t+1, \tau_{1}}\right)\right]+\tau_{2} \gamma u\left(\bar{c}_{t+2, \tau_{2}}\right)
$$

subject to $(1)-(3)$ and $0 \leq \bar{\epsilon}_{t, \tau_{0}}<1,0<\bar{l}_{t+1, \tau_{1}} \leq 1$. Here, $\beta>0$ and $\gamma>0$ denote discount factors capturing pure time preference as well as utility weights for consumption experienced in an active and healthy state $(\beta)$ and in a retired and potentially frail state $(\gamma)$. In each period the utility per time increment is aggregated over the length of the period such that a higher weight is attached to longer periods. Formally, utility per time increment is multiplied by period length $\tau_{0}, \tau_{1}$ and $\tau_{2}$. We assume decreasing marginal utility from consumption, i.e. $u^{\prime}>0, u^{\prime \prime}<0$, and a well-behaved function for disutility from work, such that the first order conditions provide a 
maximum. We allow the disutility experienced from labor supply to be potentially increasing with age, $\partial v / \partial a \geq 0$, which provides a simple device to introduce age-dependent, gradual withdrawal from the labor market. Substituting (1)-(3) into (4), it is straightforward to see that the first order conditions for the interior solution for optimal education, labor supply, and savings are given by:

$$
\begin{gathered}
\bar{w}_{t, \tau_{0}} u^{\prime}\left(\bar{c}_{t, \tau_{0}}\right)=\beta \tau_{1} u^{\prime}\left(\bar{c}_{t+1, \tau_{1}}\right) h^{\prime}\left(\bar{\epsilon}_{t, \tau_{0}}\right) \bar{l}_{t+1, \tau_{1}} \bar{w}_{t+1, \tau_{1}} \\
u^{\prime}\left(\bar{c}_{t+1, \tau_{1}}\right) h\left(\bar{\epsilon}_{t, \tau_{0}}\right) \bar{w}_{t+1, \tau_{1}}=v^{\prime}\left(a, \bar{l}_{t+1, \tau_{1}}\right) \\
\beta u^{\prime}\left(\bar{c}_{t+1, \tau_{1}}\right)=\gamma \widetilde{R}_{t+1, \tau_{1}} u^{\prime}\left(\bar{c}_{t+2, \tau_{2}}\right) .
\end{gathered}
$$

\subsection{Education and Labor Supply: The Mechanism in General. Condition (5) requires} that the marginal cost of education in terms of foregone labor income evaluated in terms of marginal utility from consumption in youth (the left hand side) equals the expected marginal benefit in terms of higher income in middle age through the accumulated human capital and the associated skill premium (the term $h^{\prime}\left(\bar{\epsilon}_{t, \tau_{0}}\right) \bar{l}_{t+1, \tau_{1}} \bar{w}_{t+1, \tau_{1}}$ ), evaluated in terms of utility (the term $\left.\beta \tau_{1} u^{\prime}\left(\bar{c}_{t+1, \tau_{1}}\right)\right)$. Condition (6) requires that the benefit that one unit more of work provides, given by the term $h\left(\bar{\epsilon}_{t, \tau_{0}}\right) \bar{w}_{t+1, \tau_{1}}$, evaluated in terms of utility, $u^{\prime}\left(\bar{c}_{t+1, \tau_{1}}\right)$, equals the marginal loss in terms of foregone utility from leisure (i.e. higher disutility from work, $\left.v^{\prime}\left(a, \bar{l}_{t+1, \tau_{1}}\right)\right)$. Notice that labor supply is a within-period decision. It does not directly depend on period length or life expectancy. Condition (7) requires that the expected utility loss incurred by saving a unit of income more (the left hand side) equals the utility gain in old age that a unit of savings brings about (the right hand side).

Although life expectancy does not affect labor supply directly, it does so in an indirect way because the decisions on savings, labor supply, and education, are non-separable. This is so because education acquired in the first period $\bar{\epsilon}_{t, \tau_{0}}$ enters marginal utility from consumption in the second period, $u^{\prime}\left(\bar{c}_{t+1, \tau_{1}}\right)=u^{\prime}\left(\bar{l}_{t+1, \tau_{1}} h\left(\bar{\epsilon}_{t, \tau_{0}}\right) \bar{w}_{t+1, \tau_{1}}-\bar{s}_{t+1, \tau_{1}}\right)$ from (2). This term appears in all three optimality conditions and makes the decision on all three choice variables interdependent. Because (active) life expectancy enters the optimality conditions for education and savings, it does thus also bear upon the labor supply decision.

The effect of higher life expectancy on labor supply is generally ambiguous. In order to see this assume that higher life expectancy (larger $\tau_{1}$ or $\tau_{2}$ ) leads to more time spent on education. Below 
we show that this is always the case. More education through more human capital increases income in the second period $h\left(\bar{\epsilon}_{t, \tau_{0}}\right) \bar{w}_{t+1, \tau_{1}}$. Taken for itself the income effect makes the left hand side of (6) larger. But more income and the higher level of consumption acquired with it reduces the marginal utility from consumption, $u^{\prime}\left(\bar{l}_{t+1, \tau_{1}} h\left(\bar{\epsilon}_{t, \tau_{0}}\right) \bar{w}_{t+1, \tau_{1}}-\bar{s}_{t+1, \tau_{1}}\right)$, since $u^{\prime \prime}<0$. This substitution effect reduces the left hand side of (6). Moreover, whether individuals react to increasing income by supplying more labor depends on the sign of $v^{\prime \prime}$, another gateway for ambiguity. Whether the price effect or the substitution effect dominates depends on the shape of the utility function.

A similarly ambiguous response can be expected with respect to savings. A longer stay in the middle period of life increases the time during which middle age consumption is enjoyed. This entails an income effect that leads to higher consumption per time increment during middle age because the old age period gets relatively shorter. Taken for itself, this effect leads to lower savings. But higher life expectancy also causes more education and more income and consumption per time increment in the middle period. It thus lowers marginal utility from consumption in middle age $\left(u^{\prime}\left(\bar{c}_{t+1, \tau_{1}}\right)\right.$ decreases on the left hand side) and thus leads, taken for itself, to more consumption in old age, that is to more savings. Again, the shape of the utility function will tell which effect dominates.

2.4. Explicit Solution. In the following we assume that $u(x)=\log (x)$ and $v(a, x)=B(a) x^{1 / \eta}$ with $B(a)>0$ and $\partial B(a) / \partial a \geq 0 \forall a$, and that human capital is accumulated according to Mincer (1974) with a constant return to schooling $\theta:=\widetilde{\theta} \cdot \tau_{0}>0$ and a constant scaling factor $\omega>0$, i.e. $h\left(\bar{\epsilon}_{t, \tau_{0}}\right)=\omega \cdot \exp \left(\theta \bar{\epsilon}_{t, \tau_{0}}\right)$. These parameterizations are general enough to establish our main results but specific enough to obtain an explicit solution of the maximization problem (1)-(4). In the Appendix we show that it is given by (8)-(10).

$$
\begin{aligned}
\bar{\epsilon}_{t, \tau_{0}} & =\max \left\{0,1-\frac{1}{\theta\left(\beta \tau_{1}+\gamma \tau_{2}\right)}\right\} \\
\bar{l}_{t+1, \tau_{1}} & =\min \left\{1,\left(\frac{B(a)}{\eta}\right)^{-\eta} \cdot\left(\frac{\beta \tau_{1}}{\beta \tau_{1}+\gamma \tau_{2}}\right)^{-\eta}\right\} \\
\bar{s}_{t+1, \tau_{1}} & =\frac{\gamma \tau_{2} h\left(\bar{\epsilon}_{t, \tau_{0}}\right) \bar{l}_{t+1, \tau_{1}}}{\beta \tau_{1}+\gamma \tau_{2}} \cdot \bar{w}_{t+1, \tau_{1}}
\end{aligned}
$$


Observe from (8) that life can be so short that individuals prefer not to invest in education and remain uneducated. Observe from (9) that active life expectancy can be so low that all time in the middle period is allocated to work.

In the following we call $\eta>0$ the labor supply elasticity. But notice that $\eta$ does not stand for the labor supply elasticity in the conventional sense, i.e. evaluated with respect to the real wage. As in any available model on growth with endogenous labor supply, labor has to be inelastic with respect to the real wage in order to avoid that individuals stop working in a perpetually growing economy (Prescott, 1986). Here, the supply elasticity is measured with respect to the expected relative length of the middle period in life, $\beta \tau_{1} /\left(\beta \tau_{1}+\gamma \tau_{2}\right)$. It measures by how much labor supply declines when the middle age period gets relatively larger by one percent. Intuitively, individuals prefer to work less when the middle age period of life gets relatively longer because the same level of consumption per time increment in old age can be financed by fewer hours of work per time increment (e.g. per month) in middle age. The elasticity $\eta$ measures how strong this response is.

With respect to the interior solution $\bar{\epsilon}_{t, \tau_{0}}=1-\frac{1}{\theta\left(\beta \tau_{1}+\gamma \tau_{2}\right)}, \bar{l}_{t+1, \tau_{1}}=\left(\frac{B(a)}{\eta}\right)^{-\eta} \cdot\left(\frac{\beta \tau_{1}}{\beta \tau_{1}+\gamma \tau_{2}}\right)^{-\eta}$ and $\bar{s}_{t+1, \tau_{1}}=\frac{\gamma \tau_{2} h\left(\bar{\epsilon}_{t, \tau_{0}}\right) \bar{t}_{t+1, \tau_{1}}}{\beta \tau_{1}+\gamma \tau_{2}} \cdot \bar{w}_{t+1, \tau_{1}}$ we get the following results on comparative statics. All propositions are proved in the Appendix.

Proposition 1 (Education). The time invested in schooling $\bar{\epsilon}_{t, \tau_{0}}$ increases with the period lengths $\tau_{1}, \tau_{2}$ and the return to schooling $\theta$.

Intuitively, higher life expectancy motivates more education no matter whether it is caused by a longer middle age or old age because the fruits of education in terms of higher consumption are smoothed over the life cycle and enjoyed in all periods.

Proposition 2 (Labor Supply). Labor supply per time increment in middle age $\bar{l}_{t+1, \tau_{1}}$ decreases with active life expectancy $\left(\tau_{1}\right)$ and, if $B^{\prime}(a)>0$, with age. It increases with the duration of old age $\left(\tau_{2}\right)$.

The second part of Proposition 2 corresponds with the familiar result from the simple BenPorath mechanism: if individuals expect to live longer in the sense of a longer stay in old age, they work harder in middle age. Yet, Proposition 2 also shows that if individuals expect to stay longer in middle age, they reduce labor supply per time increment because they expect to 
finance the same level of old age consumption with less labor supply per time increment. This result, taken together with Proposition 1, provides a first reconciliation of the evidence presented in Hazan (2009) with rational decision making on human capital formation in a conventional life cycle model: higher life expectancy causes higher education as well as lower labor supply if survival improves in the middle age period, that is, if it is driven by higher active life expectancy.

We next turn from individual decisions per time increment to macro-economic aggregates per period. Here, results depend crucially on the labor supply elasticity.

Proposition 3 (Aggregate Labor Supply, ETWH). Aggregate labor supply of the middleaged generation $L_{t+1, \tau_{1}} \equiv \tau_{1} \bar{l}_{t+1, \tau_{1}}$ decreases with active life expectancy $\left(\tau_{1}\right)$ if the labor supply elasticity is sufficiently large, i.e. for $\eta>\left(\beta \tau_{1}+\gamma \tau_{2}\right) /\left(\gamma \tau_{2}\right)$.

Notice that the term $L_{t+1, \tau_{1}} \equiv \tau_{1} \bar{l}_{t+1, \tau_{1}}$ does not only measure aggregate labor supply of middle-aged persons but also total hours that young individuals expect to work during middle age. It thus captures Hazan's (2009) main variable of interest, expected total working hours (ETWH). The fact that $L$ measures labor supply during middle age (thus ignoring labor supply in youth) squares well with the fact that Hazan's computations assume labor market entry at age 20. The fact that the expectation is built at entry into the education period squares well with the fact that Hazan considers labor supply expected at age 5. Proposition 3 shows that aggregate labor supply, or ETWH, decreases with increasing active life expectancy if labor supply is sufficiently elastic. In that case the negative effect of higher active life expectancy on increasing demand for leisure per time increment in middle age is dominating the positive effect of a longer duration of middle-aged life.

Proposition 4 (Non-Monotonicity). For $\eta>1, L_{t+1, \tau_{1}}$ is minimized at $\tau_{1}=(\eta-1) \gamma \tau_{2} / \beta$.

Interestingly, a longer expected active life (higher $\tau_{1}$ ) has a non-monotonic effect on aggregate labor supply if the labor supply elasticity is sufficiently large. Originating from a relatively short active life, improving $\tau_{1}$ has the dominating effect of less labor supply per time increment. If, on the other hand, active life expectancy is already (sufficiently) high, and individuals enjoy already a lot of leisure, further improving active life length has the dominating effect of a longer working life, and total labor supply increases. In this case a period of declining labor supply, as experienced over the last century, is predicted to be transitory. If active life expectancy continues to increase, aggregate labor supply, according to the model, will eventually rise again. 
Proposition 5 (Savings Rate). Let $\tilde{s}_{t+1, \tau_{1}}:=\bar{s}_{t+1, \tau_{1}} / \bar{w}_{t+1, \tau_{1}}$ define the average savings rate per time increment. The average savings rate increases with the return to schooling $\theta$ and with the period length of old age $\tau_{2}$. It decreases with active life expectancy if the labor supply elasticity is sufficiently large, i.e.

$$
\eta>\frac{\beta \tau_{1}\left(1-\beta \tau_{1}-\gamma \tau_{2}\right)}{\gamma \tau_{2}\left(\beta \tau_{1}+\gamma \tau_{2}\right)}
$$

The aggregate savings rate, $\widetilde{S}_{t+1, \tau_{1}} \equiv \tau_{1} \tilde{s}_{t+1, \tau_{1}}$, increases with active life expectancy $\left(\tau_{1}\right)$ if the labor supply elasticity is sufficiently small, i.e. for

$$
\eta<\frac{\beta \tau_{1}+\beta \gamma \tau_{1} \tau_{2}+\gamma^{2} \tau_{2}^{2}}{\beta \gamma \tau_{1} \tau_{2}+\gamma^{2} \tau_{2}^{2}}
$$

Turning to the impact of life expectancy on savings, the model predicts that people save more when they expect to stay relatively longer in old age, that is if $\tau_{2}$ increases. The definition of the aggregate savings rate relates to the conventional savings rate obtained in a standard OLG model, in which the length of the working period is typically normalized to one. It gives the share of the generational wage (per unit of human capital) used to build up the aggregate capital stock. An increasing active life expectancy, taken for itself, has a positive impact on aggregate savings. However, individuals may response to a longer active life by saving less per time increment. Proposition 5 shows that the positive duration effect dominates the substitution effect if labor supply is sufficiently inelastic. In that case more human capital (acquired by the induced higher education) has relatively little effect on leisure. The dominating effect is higher income per time increment in middle age. Because individuals prefer a smooth consumption profile, they transfer some of the additional income to old age. Alternatively, if labor supply is highly elastic, the substitution effect, that is the induced higher demand for leisure, dominates and the aggregate savings rate declines.

\section{Calibration}

In this section we show that the simple overlapping generations model can explain the correlation between life expectancy and education and between life expectancy and labor supply (ETWH) observed for male U.S. citizens over the last 150 years (as compiled by Hazan, 2009). For that purpose we assume that the period length of the youth $\left(\tau_{0}\right)$ corresponds to 20 years and that life "begins" at age 5 . Therefore the individual is at age 25 at the end of the first period. 
As motivated in the introduction we assume that $\tau_{1}$ and $\tau_{2}$ improve in sync such that the relative length of active life gets mildly larger with improving life expectancy. Specifically, let $\underline{\tau}_{i}$ define lower bounds and $\bar{\tau}_{i}$ upper bounds for middle and old age, $i=1,2$, and let $\lambda \in[0,1]$ denote the factor of proportionality. Life expectancy at 5 is then given by a convex combination of lower and upper bound, that is by

$$
L E=\tau_{0}+(1-\lambda) \underline{\tau}_{1}+\lambda \bar{\tau}_{1}+(1-\lambda) \underline{\tau}_{2}+\lambda \bar{\tau}_{2} .
$$

We set $\tau_{0}=20, \underline{\tau}_{1}=2, \bar{\tau}_{1}=60$ and $\underline{\tau}_{2}=6, \bar{\tau}_{2}=16$. These values imply that life expectancy at 5 runs from 28 to 96 years, when $\lambda$ runs from 0 to 1 . The lower bound accords well with life expectancy in ancient and pre-industrial times (Clark, 2007, Chapter 5) and the upper bound coincides with the gerontological estimate of human life-span (Gavrilov and Gavrilova, 1992). At the same time, active life expectancy runs from 22 to 80 implying that the share of active (healthy) years rises from 0.79 initially to 0.83 , in line with the cross-country observation presented in the Introduction. ${ }^{3}$ The historical period investigated by Hazan, in which life expectancy improved from 52.5 years to 70.7 years is covered by $\lambda$ values between 0.32 and 0.6 .

For the return to education there exists a variety of estimates, depending on method and sample, but a consensus value in recent estimates for the average return to education in the US seems to be 0.1 per year of education (Card, 1999, Psacharopoulos and Patrinos, 2004). ${ }^{4}$ Since the length of the education period lasts for 20 years, we put $\theta=\widetilde{\theta} \cdot \tau_{0}=0.1 \cdot 20=2$.

With the focus on life-time labor supply we abstain, for simplicity, from introducing agedepending disutility from work. Modeling age-dependent labor supply would add more realism but conceptually it would "only" provide an unequal distribution of life-time labor supply (ETWH) across ages, leaving unaffected the association between ETWH and education, which depends on life expectancy and active life expectancy but not on the distribution of ETWH. On

\footnotetext{
3 Our estimate of the upper boundary is lower than the highest values observed in the cross-country WHO data. The deviation could be explained by our different notion of active life expectancy. The normal, aging-driven loss of cognitive skills, for example, does not affect the WHO definition of full health. It may thus be that fluid cognitive skills (creativity) have deteriorated to degree that precludes participation in the workforce, particularly in a learned occupation, although the person is otherwise in good shape and and classified as "fully" healthy. Notice also that time discounting amplifies small relative improvements of active life expectancy. The crucial factor $\beta \tau_{1} /\left(\beta \tau_{1}+\gamma \tau_{2}\right)$ improves from 0.24 to 0.85 when $\lambda$ goes from 0 to 1 .

4 Turner et al. (2007) estimate a somewhat larger return to education across US States with values between 0.11 and 0.15 in the period from 1840-2000. We could re-calibrate our model to these values by re-adjusting the time discount factors with insignificant impact on the fit of the historical data.
} 
Figure 3: Model Calibration
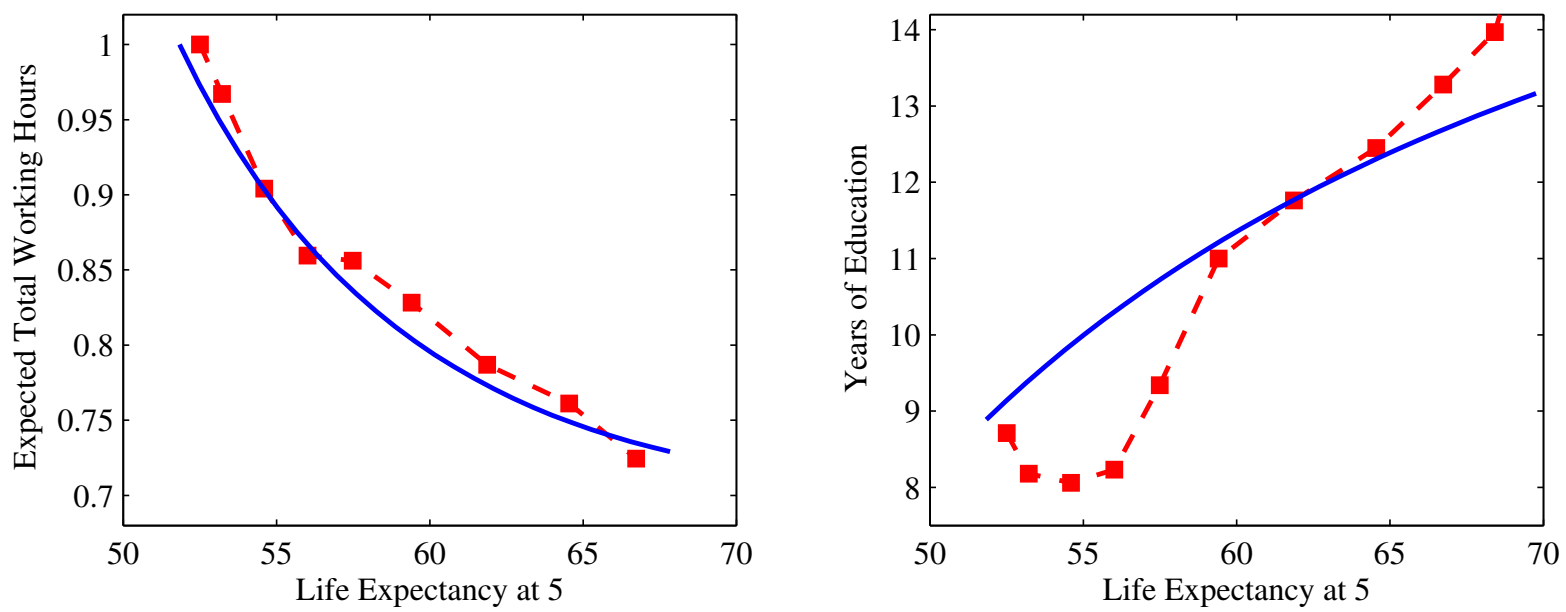

Dashed (red) lines: data from Hazan (2009). Solid (blue) lines: model predictions. Expected working hours have been normalized such that expected hours for men born 1840 (when life expectancy is 52.5 years) is equal to unity. Generational results from the model have been converted into years by assuming a unit length for a period of 20 years (i.e., for example $\bar{\epsilon}_{t, \tau_{0}}=0.4$ is converted to 8 years of education.

the macro-side, age-dependent labor supply, would severely complicate the aggregation across cohorts and destroy the simplicity of the model. Setting $B(a)=\bar{B}$ we thus estimate $\bar{B}, \beta$, $\gamma$, and $\eta$ such that the model fits the data on labor supply (ETWH) and years of education compiled by Hazan (2009). This leads to the estimates $\beta=0.65, \gamma=0.42, \eta=8.47$ and $\bar{B}=11.8$ and the results shown in Figure 3. Dashed lines display the data from Hazan and solid lines show the predictions of the model. The model fits the historical data quite well. The fit is somewhat better for ETWH than for education because, naturally, the simple Mincerian equation cannot capture the non-monotonicity observed for education for the 1860 to 1880 cohort (when life expectancy was around 55 years). Furthermore the model predicts a mildly concave correlation of education and life expectancy, which is hardly visible in the data.

For better assessment we normalized the highest value of ETWH to unity. In line with the data the model predicts that ETWH decreases by about 30 percent as life expectancy increases from 52 to 66 years (for obvious reasons the Hazan data ends with the cohort born 1930). At the same time the model predicts that education increases from 9 years to 13 years as life expectancy increases from 52 to 66 years. Overall, it is hard to argue that the predictions from the life-cycle model are inconsistent with the historical data. Increasing life expectancy causes labor supply (ETWH) to fall and years of schooling to rise. 


\section{General Equilibrium and Long-Run Adjustment Dynamics}

4.1. Setup. In order to evaluate the model's implications for long-run development we integrate education, labor supply, and savings from the life-cycle model into a simple dynamic general equilibrium setup. The unit period for the dynamic macro-economy equals one year. This means that at any unit period there are several middle aged generations active on the labor market. In a slight abuse of notation let $t$ now denote the time period as well as the birth year of a cohort whereas $j$ denotes the age of a cohort measured in unit periods. Let $\tau_{1, t}$ denote the length of middle age of the generation which enters middle age at time $t$. This means that aggregate labor supply (hours worked) in period $t$ is computed as

$$
\tilde{L}_{t}=1-\bar{\epsilon}_{t, \tau_{0}}+\sum_{j=0}^{\bar{\tau}_{1}} \max \left\{0, \min \left\{\tau_{1, t}-j, 1\right\}\right\} \cdot \bar{l}_{t-j, \tau_{1, t-j}} .
$$

Likewise, aggregate effective labor supply, or human capital, is computed as

$$
H_{t}=1-\bar{\epsilon}_{t, \tau_{0}}+\sum_{j=0}^{\bar{\tau}_{1}} \max \left\{0, \min \left\{\tau_{1, t}-j, 1\right\}\right\} \cdot \bar{l}_{t-j, \tau_{1, t-j}} \cdot h\left(\bar{\epsilon}_{t-j-1, \tau_{0}}\right) .
$$

We assume that individuals correctly predict their effective life expectancy. Allowing for mistakes, for example, by assuming instead adaptive expectation (young individuals expect the active life-length observed for their parents or grandparents) would only mildly modify the predicted adjustment dynamics.

Aggregate savings per period are obtained from savings of the currently alive middle-aged generations as

$$
\hat{S}_{t}=\sum_{j=0}^{\bar{\tau}_{1}} \max \left\{0, \min \left\{\tau_{1, t-j}, \quad 1\right\}\right\} \cdot \frac{\gamma \tau_{2, t-j}}{\beta \tau_{1, t-j}+\gamma \tau_{2, t-j}} \cdot \bar{l}_{t-j, \tau_{1, t-j}} \cdot h\left(\bar{\epsilon}_{t-j-1, \tau_{0}}\right) \cdot w_{t} .
$$

Following the OLG tradition, we assume that this period's savings are available as aggregate capital stock next period and impose full depreciation of capital within a period, $K_{t+1}=\hat{S}_{t}$. Aggregate capital and effective labor supply are combined by a Cobb-Douglas production function to produce aggregate output $Y_{t}=A_{t} K_{t}^{\alpha} H_{t}^{1-\alpha}$, implying that the unit wage is given by $w_{t}=(1-\alpha) A_{t} K_{t}^{\alpha} H_{t}^{-\alpha}$. The parameter $A_{t}$ captures total factor productivity (TFP).

Following a core idea of unified growth theory (Galor, 2005, 2011) we assume that the total level of education of the young generation has a positive impact on state of technology in the next 
period. Similar to Cervellati and Sunde (2005) we impose a Cobb-Douglas technology, which also allows for a positive but diminishing external effect from the currently available knowledge to the creation of new knowledge. This means that advances of technology (TFP) are given by

$$
A_{t+1}-A_{t}=\delta \cdot\left(\widetilde{\epsilon}_{t}\right)^{\psi} \cdot A_{t}^{\phi}
$$

with $\delta>0,0<\phi \leq 1$ and $0<\psi<1$. Here, $\widetilde{\epsilon}_{t}$ denotes the education level of the currently youngest middle aged generation. Notice that $\widetilde{\epsilon}_{t}$ changes only every 20 years because a new generation enters only every 20 years and the length of the first period equals 20 years as well. Thus the "rhythm" of the macro economy is 20 years, an assumption which greatly simplifies the analysis.

The final element that closes the model is a feedback effect from the state of economic development to life expectancy. For simplicity, we follow again Cervellati and Sunde (2005) and assume a positive impact of the current generation's level of education on the next generation's life expectancy. A straight forward way to implement this notion is to utilize the upper and lower bounds introduced in the calibration section, $\underline{\tau}_{i}, \bar{\tau}_{i}, i=1,2$, and assume that lower bounds (life expectancy of 28 years) apply without any education in the population and upper bounds (life expectancy equals life-span) apply at maximum education. Actual (active) life expectancy is then determined by the current level of education as a convex combination of the boundaries:

$$
\tau_{i, t}=\left(1-\widetilde{\epsilon}_{t-1}\right) \underline{\tau}_{i}+\widetilde{\epsilon}_{t-1} \bar{\tau}_{i}, \quad i=1,2 .
$$

This way of modeling preserves the basic idea of life expectancy, $\tau_{0}+\tau_{1}+\tau_{2}$, and active life expectancy, $\tau_{0}+\tau_{1}$, evolving in sync and introduces a simple positive feedback effect of education on longevity. Notice that the demographic variable depends on the aggregate level of education implying that they change only every 20 years as well. Another implication of the simple form (15) is that the long-run steady-state is easily assessed. Given convergence towards a constant positive level of education, the remaining dynamics depend on $\phi$. For $\phi=1$ we have the endogenous growth case and the economy approaches a constant positive growth rate of technology and GDP. For $\phi<1$ we have the semi-endogenous growth case with zero growth along the balanced growth path, that is for time approaching infinity. For this paper, however, the outlook predicted for the distant future is less interesting than the model's performance in explaining the past and the present. 
4.2. Steady-State. Although the setup was deliberately simply constructed, it allows for a multitude of steady-states. In particular, if model parameters support a corner solution for education, there may exist a longevity-driven poverty trap without education and a growth path with constant positive education. These locally stable steady-states are separated by an unstable steady-state. In order to see this, insert (15) into (8) to get a first order difference equation for education:

$$
\widetilde{\epsilon}_{t}=\max \left\{0, \tau_{0}\left(1-\frac{1}{\theta\left(\beta\left(\underline{\tau}_{1}+\widetilde{\epsilon}_{t-1}\left(\bar{\tau}_{1}-\underline{\tau}_{1}\right)\right)+\gamma\left(\underline{\tau}_{2}+\widetilde{\epsilon}_{t-1}\left(\bar{\tau}_{2}-\underline{\tau}_{2}\right)\right)\right)}\right)\right\} .
$$

At a steady-state education is constant, implying $\widetilde{\epsilon}_{t}=\widetilde{\epsilon}_{t-1}=\tilde{\epsilon}^{*}$. Inserting this into equation (16) we obtain steady-state education

$$
\tilde{\epsilon}^{*}=\frac{\beta\left(\tau_{0} \bar{\tau}_{1}-\left(1+\tau_{0}\right) \underline{\tau}_{1}\right)+\gamma\left(\tau_{0} \bar{\tau}_{2}-\left(1+\tau_{0}\right) \underline{\tau}_{2}\right) \pm \sqrt{D} / \sqrt{\theta}}{2\left(\beta\left(\bar{\tau}_{1}-\underline{\tau}_{1}\right)+\gamma\left(\bar{\tau}_{2}-\underline{\tau}_{2}\right)\right)}
$$

with

$D=4 \tau_{0}\left(\theta\left(\beta \underline{\tau}_{1}+\gamma \underline{\tau}_{2}\right)-1\right)\left(\beta\left(\bar{\tau}_{1}-\underline{\tau}_{1}\right)+\gamma\left(\bar{\tau}_{2}-\underline{\tau}_{2}\right)\right)+\theta\left(\beta\left(\left(1+\tau_{0}\right) \underline{\tau}_{1}-\tau_{0} \bar{\tau}_{1}\right)+\gamma\left(\left(1+\tau_{0}\right) \underline{\tau}_{2}-\tau_{0} \bar{\tau}_{2}\right)\right)^{2}$.

There exist two real, non-trivial steady states, if the discriminant (17) is positive, that is for

$$
\theta>\bar{\theta} \equiv \frac{4 \tau_{0}\left(\beta\left(\bar{\tau}_{1}-\underline{\tau}_{1}\right)+\gamma\left(\bar{\tau}_{2}-\underline{\tau}_{2}\right)\right)}{\left(\beta\left(\underline{\tau}_{1}+\tau_{0}\left(\bar{\tau}_{1}-\underline{\tau}_{1}\right)\right)+\gamma\left(\underline{\tau}_{2}+\tau_{0}\left(\bar{\tau}_{2}-\underline{\tau}_{2}\right)\right)\right)^{2}} .
$$

For $\theta<\bar{\theta}$, the discriminant is negative and there exists no positive real solution for education. The only remaining solution is $\tilde{\epsilon}^{*}=0$. If the return to schooling, $\theta$, is sufficiently low, individuals always prefer to remain uneducated.

Figure 4 illustrates the case of three steady states, two positive ones, and a trivial one. The curve for education in period $t$ is according to (16) concave. Steady-states are observed at the intersections with the identity line. Above the identity line there is $\widetilde{\epsilon}_{t}>\widetilde{\epsilon}_{t-1}$, and it is easy to see that one positive steady-state is unstable $\left(\widetilde{\epsilon}_{1}\right)$, separating the two locally stable equilibria $\left(\widetilde{\epsilon}_{0}, \widetilde{\epsilon}_{2}\right)$.

On the other hand, if the corner solution does not exist, the concave curve according to (16) intersects the identity line exactly once, implying a unique and globally stable steady-state.

4.3. Calibration and Results. For the macro-economy we keep all parameter values from the calibration of the individual life cycle model of Section 3. An implication is that there 
Figure 4: Multiple Education Equilibria

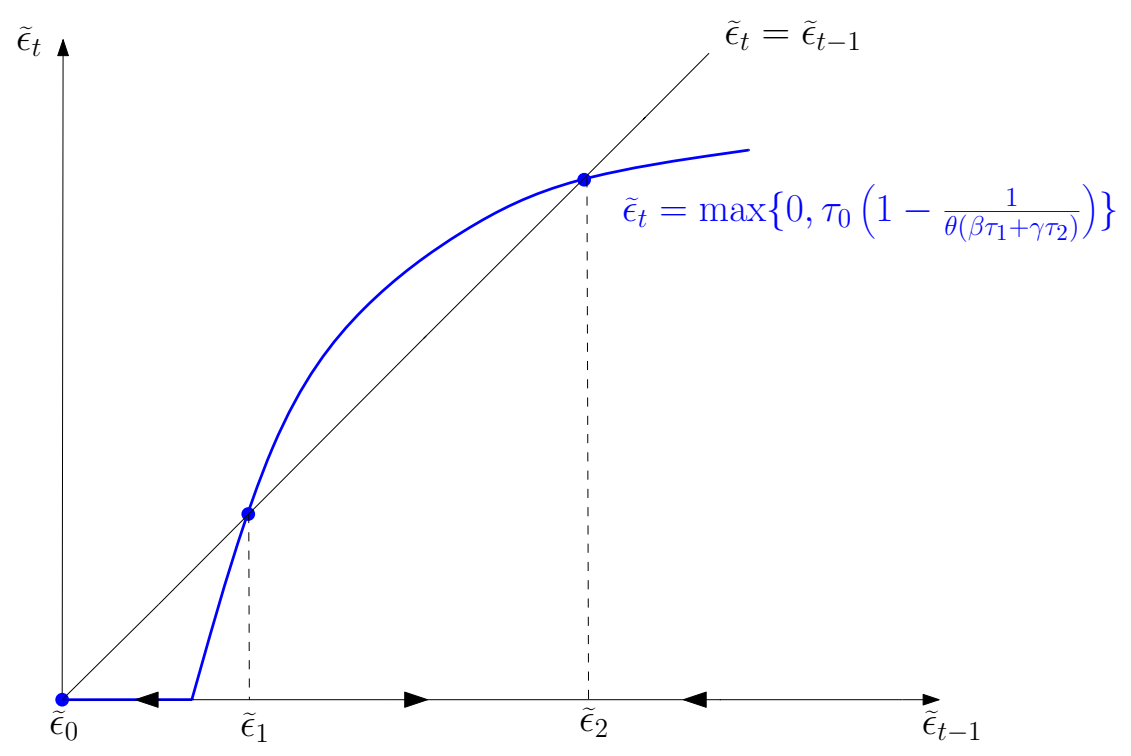

exists no corner solution. The steady-state is unique. We set $\omega=0.5$ such that the savings rate (investment rate) approaches 0.17 percent as observed for the US in the late 20th century. Following the growth literature we set the capital share $\alpha=1 / 3$. Finally we set the knowledge parameters such that TFP growth reaches a maximum in the 1970s and growth of GDP per worker is about 2 percent in the late 20th century. This leads to the estimates $\delta=0.5, \psi=0.95$, and $\phi=0.95$. The economy starts in the year $0 \mathrm{AD}$ with $A_{0}=1000$.

Figure 5 and 6 present the predicted adjustment dynamics for the most interesting epoch from 1700 to today. Solid lines in Figure 5 show the trajectories for life expectancy, education, and labor supply. Dashed lines show the historical data from Hazan (2009). Increasing life expectancy causes years of schooling to rise and aggregate labor supply (ETWH) first to rise and then to fall. The initial rise of ETWH results solely from increasing active life expectancy because, according to the model, labor supply is at the corner before 1850 and a longer healthy life thus translates one to one into more aggregate labor supply. After 1850, individuals increasingly enjoy leisure time and ETWH declines.

Compared with the historical evolution the model predicts a somewhat too steep increase of life expectancy, a somewhat too flat increase of years of schooling, and a somewhat too late decline of labor supply. But overall, it is hard to argue that the model's predictions are contradicted by the data. Interestingly, the model predicts also that labor supply stops declining roughly 
at the end of Hazan's period of observation, that is for cohorts born in the second half of the 20th century. This prediction seems in line with the evidence in Ramey and Francis (2009) for hours worked per employed person (see below). The turning point for labor supply, however, theoretically identified in Proposition 4, is outside the relevant numerical range of Figure 5. Ceteris paribus, it would be found where $\tau_{1}=77.8$, that is for an active life expectancy of 97.8 years.

Figure 6 shows the implications for economic growth, aggregate savings, and TFP. For comparison, the first panel reiterates the longevity trajectory from Figure 5. Note that the abscissa is now indexed by year (no longer by birth year of cohort as in Figure 5). Increasing life expectancy, with some delay, causes a gradually increasing growth rate of TFP, which reaches a maximum in the 1970s. Since returns are only mildly decreasing $(\phi=0.95)$, the decline of TFP

Figure 5: Long Run Evolution of Longevity, Education, and Labor Supply
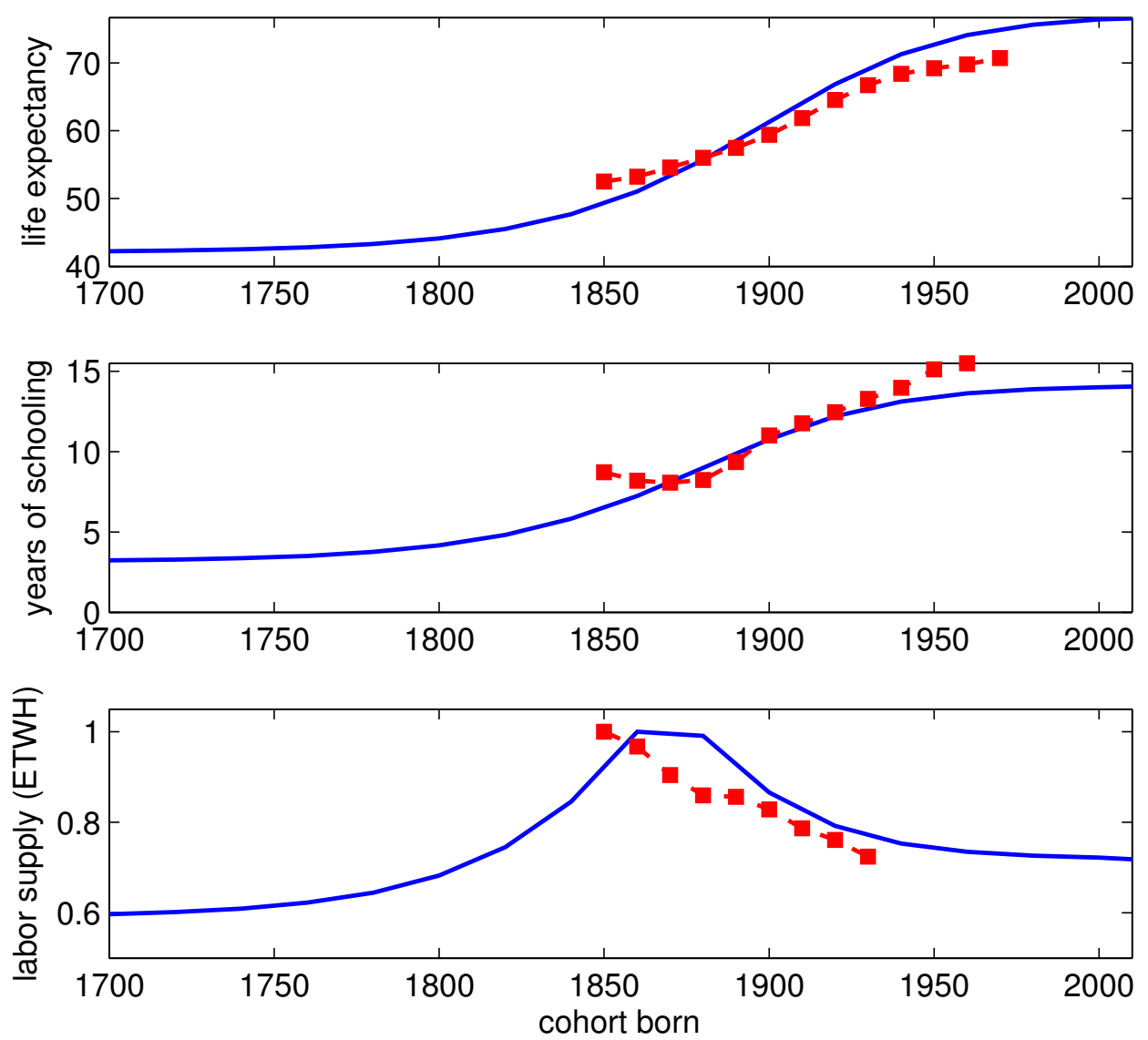

Solid lines: model prediction, dashed lines: historical data (Hazan, 2009). Labor supply is normalized such that the historical peak is at unity. A model period is translated into 20 years. 
growth is not yet markedly visible in the trajectory, it looks more like a plateau for the second half of the 20th century.

For the savings rate per time increment (dashed line) the model predicts an almost constant profile for pre-industrial times and a decline with the onset of the Second Industrial Revolution (around 1860). The aggregate savings rate of middle-age aged adults (solid line) is predicted to increase before and during the industrialization period, in line with the historical observation for Britain (Crafts, 1985). This outcome simply reflects the fact that people have increasingly more

Figure 6: Long Run Evolution of TFP Growth, Aggregate Savings, and Growth of GDP per Capita
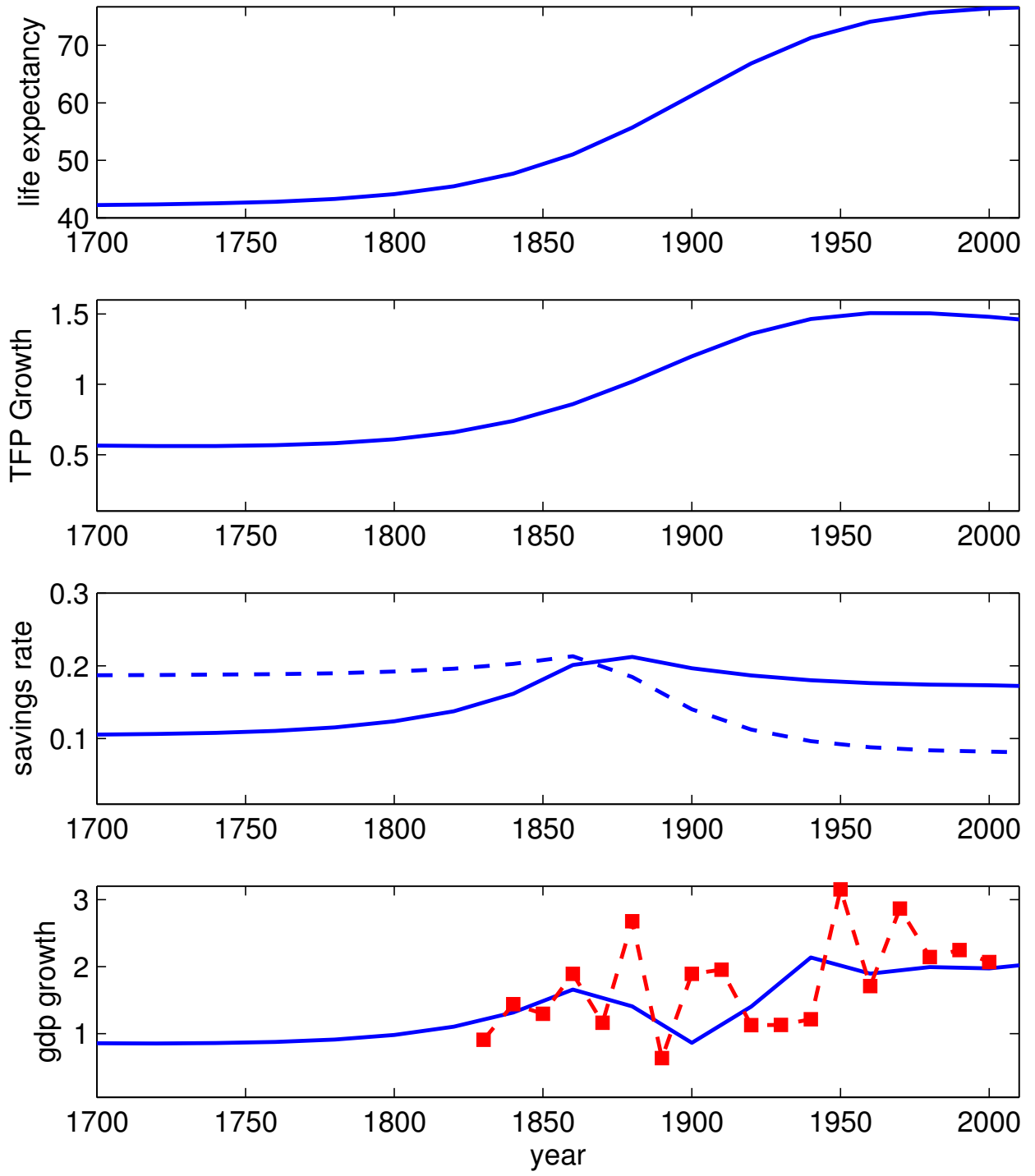

Solid lines: model prediction, dashed (red) lines: historical data for (Maddison, 2003). GDP growth is the annual growth rate of GDP per capita. Savings rate panel: solid line: aggregate savings rate during middle age $\tau_{1} s$, dashed line: savings rate per time increment $s$. 
years of active life at their disposal to accumulate wealth. For the 20th century the aggregate savings rate is predicted to stabilize at a plateau of about 17 percent, in line with the historical observation for the US (Maddison, 1992).

During the Second Industrial Revolution the growth rate of GDP is predicted to largely surpass TFP growth, in line with the historical evidence for Britain (Crafts and Harley, 1992) and the US (Gordon, 1999). Dashed lines in the GDP panel show annual GDP growth rates per decade for the US computed from the Maddison (2003) data. During industrialization, according to the model, GDP growth is quite high relative to TFP growth because it is fueled by increasing labor supply and higher aggregate savings, which in turn are driven by a longer duration of active life. For the first half of the 20th century the model predicts a declining growth rate of GDP per worker (yet an increasing growth rate of GDP per working hour) due to the declining labor supply. For the second half of the 20th century labor supply has stabilized at a low level and the growth rate of GDP increases mildly, fueled by increasing TFP growth, after which it stays (observationally) constant for the rest of the century.

4.4. Re-interpretation: A Century of Work and Leisure. So far we imagined the individual of our model as a male US American in order to match Hazan's (2009) data. The picture changes, however, if we imagine the individual as a representative (unisex) member of a household consisting actually of husband and wife. Francis and Ramey (2009) have demonstrated that the declining labor supply of US males over the last century has been accompanied by a rising labor supply of females. As a consequence, average labor supply of prime age adults displayed no discernable time trend. Average labor supply declined basically as a result of less labor supplied in youth and old age. While labor supply in youth was largely substituted by education, increasing leisure in old age was largely a result of increasing length of life.

In order to take the alternative notion of "the individual" into account we recalibrate the model such that it approximates Ramey and Francis' (2009) data. For that purpose we keep all parameters from the benchmark run but set $\eta=0.4$. Given the much lower labor supply elasticity, the response of labor supply to increasing active life expectancy turns out to be much smaller. Results are shown in Figure 7. For better comparison the upper two panels re-iterate results for life expectancy and education, which are the same as for the benchmark model. Only results on labor supply are affected. Dashed lines show the data from Francis and Ramey. 
Figure 7: A Century of Work and Leisure
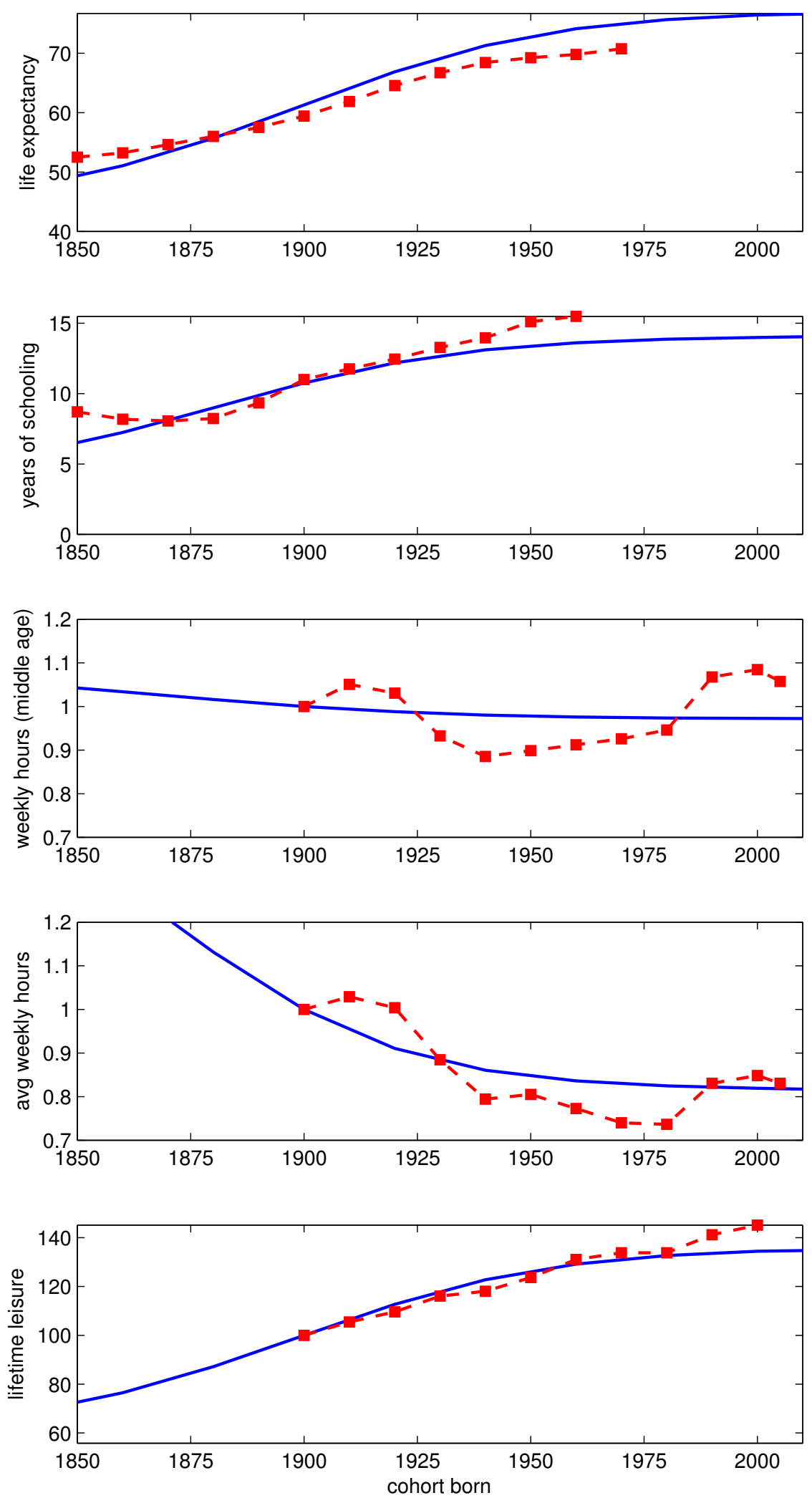

Solid lines: model prediction, dashed lines: data from Hazan (2009) for life expectancy and education and from Ramey and Francis (2009) for hours worked and leisure. See text for details. 
The third and forth panel show average labor supply per time increment of middle aged adults, that is $\bar{l}_{t+1, \tau_{1}}$ for the generation born in $t+1-\tau_{0}$, and average labor supply per time increment over the life cycle, $\hat{l}_{t} \equiv\left(\tau_{0}\left(1-\bar{\epsilon}_{t, \tau_{0}}\right)+\tau_{1, t} \bar{l}_{t+1, \tau_{1}}\right) /\left(\tau_{0}+\tau_{1, t}+\tau_{2, t}\right)$ for the generation born at $t$. The variable $\bar{l}_{t+1, \tau_{1}}$ corresponds with average weekly hours of 25 -54 year old persons in Ramey and Francis (2009) and the variable $\hat{l}$ corresponds with average life-long weekly hours of persons above age 14. For better comparison we have chosen the same scale for both panels and normalized the values obtained for 1900 to unity for both time series. The re-calibrated model matches the Ramey and Francis data reasonably well. In particular, there is little change of weekly labor supply of middle-aged adults while average weekly hours drop by about 20 percent during the course of the century because of less labor supply of the young and a longer life of the old.

The final panel shows total life-time leisure, computed as $\ell_{t} \equiv\left[\tau_{1, t}\left(1-\bar{l}_{t+1, \tau_{1}}\right)+\tau_{2, t}\right] /\left(\tau_{0}+\right.$ $\left.\tau_{1, t}+\tau_{2, t}\right)$ for the generation born at $t$. The prediction of the model is confronted with the Ramey and Francis data, both series are normalized to 100 in the year 1900. The model matches the 40 percent increase of total leisure during the last century reasonably well. In theory as well as in the data, this tremendous increase is largely explained by a longer life in old age.

\section{CONCLUSION}

In this paper we proposed a simple life cycle model that reconciles theory with evidence on the historical evolution of life expectancy, education, and labor supply. In particular, our theory predicts that increasing life expectancy causes more education and, if the labor supply elasticity is sufficiently high, less life-time labor supply. The key mechanism is that increasing life expectancy is associated with increasing active life expectancy and that the active and healthy part of life increases (mildly) relative to the inactive and frail part. This entails an income and substitution effect. If labor supply is sufficiently elastic, the substitution effect dominates and aggregate labor supply in middle age declines. The mechanism re-establishes increasing life expectancy as a driving force of education and long-run growth. We have demonstrated the quantitative importance of this fact by a calibration with US Data. Increasing life expectancy explains the historical evolution of education, labor supply, and economic growth in the US since the 1830 s reasonably well. 
The notion of the "representative" individual in the model determines how strongly labor supply reacts to increasing life expectancy. A calibration with respect to males requires a relatively high elasticity of labor supply to match the historical data (as in Hazan, 2009). A calibration with respect to a unisex average member of a two sex household, requires a much lower supply elasticity to match the data (as in Ramey and Francis, 2009). The main point of the paper is thus quite general: no matter how the representative individual is conceptualized, observing simultaneously increasing education and declining labor supply does not contradict the life-cycle model and its prediction of increasing life expectancy as a powerful driver of education and economic development. 
Appendix A. Derivation of the optimal values $\bar{\epsilon}_{t, \tau_{0}}, \bar{l}_{t+1, \tau_{1}}, \bar{s}_{t+1, \tau_{1}}$

To obtain the globally optimal solution both the interior solution and the corner solutions have to be considered. The local optimum or interior solution is derived from the FOCs (5), (6), (7) as follows. Inserting both $u(x)=\log (x)$ and $v(x)=B x^{\frac{1}{\eta}}$ into these yields with (2) and (3)

$$
\begin{gathered}
\frac{1}{1-\bar{\epsilon}_{t, \tau_{0}}}=\frac{\beta \tau_{1}}{\bar{l}_{t+1, \tau_{1}} h\left(\bar{\epsilon}_{t, \tau_{0}}\right) \bar{w}_{t+1, \tau_{1}}-\bar{s}_{t+1, \tau_{1}}} h^{\prime}\left(\bar{\epsilon}_{t, \tau_{0}}\right) \bar{l}_{t+1, \tau_{1}} \bar{w}_{t+1, \tau_{1}} \\
\frac{h\left(\bar{\epsilon}_{t, \tau_{0}}\right) \bar{w}_{t+1, \tau_{1}}}{\bar{l}_{t+1, \tau_{1}} h\left(\bar{\epsilon}_{t, \tau_{0}}\right) \bar{w}_{t+1, \tau_{1}}-\bar{s}_{t+1, \tau_{1}}}=\frac{1}{\eta} \cdot B \cdot\left(\bar{l}_{t+1, \tau_{1}}\right)^{\frac{1-\eta}{\eta}} \\
\frac{\tau_{1} \beta}{\bar{l}_{t+1, \tau_{1}} h\left(\bar{\epsilon}_{t, \tau_{0}}\right) \bar{w}_{t+1, \tau_{1}}-\bar{s}_{t+1, \tau_{1}}}=\frac{\gamma \tau_{2}}{\bar{s}_{t+1, \tau_{1}}} .
\end{gathered}
$$

Rearranging Equation (A.3) to obtain

$$
\frac{1}{h\left(\bar{\epsilon}_{t, \tau_{0}}\right) \bar{l}_{t+1, \tau_{1}} \bar{w}_{t+1, \tau_{1}}-\bar{s}_{t+1, \tau_{1}}}=\frac{\gamma \tau_{2}}{\bar{s}_{t+1, \tau_{1}} \tau_{1} \beta} \quad \Leftrightarrow \quad \bar{s}_{t+1, \tau_{1}}=\frac{\gamma \tau_{2} \bar{l}_{t+1, \tau_{1}} h\left(\bar{\epsilon}_{t, \tau_{0}}\right) \bar{w}_{t+1, \tau_{1}}}{\beta \tau_{1}+\gamma \tau_{2}}
$$

and insert this into Equation (A.1) yields

$$
\begin{gathered}
\left(1-\bar{\epsilon}_{t, \tau_{0}}\right) \beta \tau_{1} h^{\prime}\left(\bar{\epsilon}_{t, \tau_{0}}\right) \bar{l}_{t+1, \tau_{1}} \bar{w}_{t+1, \tau_{1}}=\bar{l}_{t+1, \tau_{1}} h\left(\bar{\epsilon}_{t, \tau_{0}}\right) \bar{w}_{t+1, \tau_{1}}-\bar{s}_{t+1, \tau_{1}} \\
\Leftrightarrow \quad\left(1-\bar{\epsilon}_{t, \tau_{0}}\right) \beta \tau_{1} h^{\prime}\left(\bar{\epsilon}_{t, \tau_{0}}\right) \bar{l}_{t+1, \tau_{1}} \bar{w}_{t+1, \tau_{1}}=\bar{l}_{t+1, \tau_{1}} h\left(\bar{\epsilon}_{t, \tau_{0}}\right) \bar{w}_{t+1, \tau_{1}}-\frac{\gamma \tau_{2} \bar{l}_{t+1, \tau_{1}} h\left(\bar{\epsilon}_{t, \tau_{0}}\right) \bar{w}_{t+1, \tau_{1}}}{\tau_{1} \beta+\gamma \tau_{2}} \\
\Leftrightarrow \quad \bar{\epsilon}_{t, \tau_{0}}=1-\frac{h\left(\bar{\epsilon}_{t, \tau_{0}}\right)}{h^{\prime}\left(\bar{\epsilon}_{t, \tau_{0}}\right)} \frac{1}{\beta \tau_{1}+\gamma \tau_{2}} .
\end{gathered}
$$

Let $h\left(\bar{\epsilon}_{t, \tau_{0}}\right)=\omega \cdot \exp \left(\theta \bar{\epsilon}_{t, \tau_{0}}\right)$, then $\frac{h\left(\bar{\epsilon}_{t, \tau_{0}}\right)}{h^{\prime}\left(\bar{\epsilon}_{t, \tau_{0}}\right)}=\frac{1}{\theta}$. Hence, the interior solution for the optimal schooling time is

$$
\bar{\epsilon}_{t, \tau_{0}}=1-\frac{1}{\gamma \theta \tau_{2}+\beta \theta \tau_{1}} .
$$

Rearranging Equation (A.2) and using (A.4) yields

$$
\begin{gathered}
\quad \frac{1}{\bar{l}_{t+1, \tau_{1}} h\left(\bar{\epsilon}_{t, \tau_{0}}\right) \bar{w}_{t+1, \tau_{1}}-\bar{s}_{t+1, \tau_{1}}}=\frac{\frac{1}{\eta} B\left(\bar{l}_{t+1, \tau_{1}}\right)^{\frac{1-\eta}{\eta}}}{h\left(\bar{\epsilon}_{t, \tau_{0}}\right) \bar{w}_{t+1, \tau_{1}}} \\
\Leftrightarrow \quad h\left(\bar{\epsilon}_{t, \tau_{0}}\right) \bar{w}_{t+1, \tau_{1}}=\frac{1}{\eta} B\left(\bar{l}_{t+1, \tau_{1}}\right)^{\frac{1-\eta}{\eta}}\left(\bar{l}_{t+1, \tau_{1}} h\left(\bar{\epsilon}_{t, \tau_{0}}\right) \bar{w}_{t+1, \tau_{1}}-\frac{\gamma \tau_{2} \bar{l}_{t+1, \tau_{1}} h\left(\bar{\epsilon}_{t, \tau_{0}}\right) \bar{w}_{t+1, \tau_{1}}}{\beta \tau_{1}+\gamma \tau_{2}}\right) \\
\Leftrightarrow \quad \bar{l}_{t+1, \tau_{1}}=\left(\frac{\beta \tau_{1}+\gamma \tau_{2}}{\beta \tau_{1} B \frac{1}{\eta}}\right)^{\eta} .
\end{gathered}
$$

The optimal savings rate follows by inserting the optimal schooling time $\bar{\epsilon}_{t, \tau_{0}}$ from (A.5) and the optimal labor supply $l$ from (A.6) into equation (A.4). Furthermore, the interior solution is unique in $\mathbb{R} \times \mathbb{R}_{>0} \times \mathbb{R}$.

$$
\tilde{s}_{t+1, \tau_{1}}=\frac{\gamma \tau_{2} h\left(\bar{\epsilon}_{t, \tau_{0}}\right) \bar{l}_{t+1, \tau_{1}}}{\beta \tau_{1}+\gamma \tau_{2}}
$$


If the Hessian of $U$ is negative definite in the critical point $(\epsilon, s, l)$, then this point is a local maximum. The Hessian of $U$, c.f. (4), with $u(x)=\log (x)$ and $v(x)=B \cdot x^{\frac{1}{\eta}}$ is

$H_{U}\left(\bar{\epsilon}_{t, \tau_{0}}, \bar{l}_{t+1, \tau_{1}}, \bar{s}_{t+1, \tau_{1}}\right):=\left(\begin{array}{ccc}\frac{\partial^{2} U}{\partial \bar{s}_{t+1, \tau_{1}}^{2}} & \frac{\partial^{2} U}{\partial \bar{s}_{t+1, \tau_{1}} \partial \bar{\epsilon}_{t, \tau_{0}}} & \frac{\partial^{2} U}{\partial \bar{s}_{t+1, \tau_{1}} \partial \bar{l}_{t+1, \tau_{1}}} \\ \frac{\partial^{2} U}{\partial \bar{\epsilon}_{t, \tau_{0}} \partial \bar{s}_{t+1, \tau_{1}}} & \frac{\partial^{2} U}{\partial \bar{\epsilon}_{t, \tau_{0}}} & \frac{\partial^{2} U}{\partial \bar{\epsilon}_{t, \tau_{0}} \partial l_{t+1, \tau_{1}}} \\ \frac{\partial^{2} U}{\partial \bar{l}_{t+1, \tau_{1}} \partial \bar{s}_{t+1, \tau_{1}}} & \frac{\partial^{2} U}{\partial \bar{l}_{t+1, \tau_{1}} \partial e_{t}} & \frac{\partial^{2} U}{\partial l_{t+1, \tau_{1}}^{2}}\end{array}\right)=:\left(\begin{array}{ccc}H_{1,1} & H_{1,2} & H_{1,3} \\ H_{2,1} & H_{2,2} & H_{2,3} \\ H_{3,1} & H_{3,2} & H_{3,3}\end{array}\right)$

with

$$
\begin{aligned}
& H_{1,1}=-\frac{\beta \tau_{1}}{\left(\bar{s}_{t+1, \tau_{1}}-h\left(\bar{\epsilon}_{t, \tau_{0}}\right) \bar{l}_{t+1, \tau_{1}} \bar{w}_{t+1, \tau_{1}}\right)^{2}}-\frac{\gamma \tau_{2}}{\bar{s}_{t+1, \tau_{1}}^{2}}, \\
& H_{1,2}=\frac{h\left(\bar{\epsilon}_{t, \tau_{0}}\right) \bar{l}_{t+1, \tau_{1}} \bar{w}_{t+1, \tau_{1}} \beta \theta \tau_{1}}{\left(\bar{s}_{t+1, \tau_{1}}-h\left(\bar{\epsilon}_{t, \tau_{0}}\right) \bar{l}_{t+1, \tau_{1}} \bar{w}_{t+1, \tau_{1}}\right)^{2}}, \\
& H_{1,3}=\frac{h\left(\bar{\epsilon}_{t, \tau_{0}}\right) \bar{w}_{t+1, \tau_{1}} \beta \tau_{1}}{\left(\bar{s}_{t+1, \tau_{1}}-h\left(\bar{\epsilon}_{t, \tau_{0}}\right) \bar{l}_{t+1, \tau_{1}} \bar{w}_{t+1, \tau_{1}}\right)^{2}}, \\
& H_{2,1}=H_{1,2}, \\
& H_{2,2}=-\frac{1}{\left(1-\bar{\epsilon}_{t, \tau_{0}}\right)^{2}}-\frac{h\left(\bar{\epsilon}_{t, \tau_{0}}\right) \bar{l}_{t+1, \tau_{1}} \bar{s}_{t+1, \tau_{1}} \bar{w}_{t+1, \tau_{1}} \beta \theta^{2} \tau_{1}}{\left(\bar{s}_{t+1, \tau_{1}}-h\left(\bar{\epsilon}_{t, \tau_{0}}\right) \bar{l}_{t+1, \tau_{1}} \bar{w}_{t+1, \tau_{1}}\right)^{2}}, \\
& H_{2,3}=-\frac{h\left(\bar{\epsilon}_{t, \tau_{0}}\right) \bar{s}_{t+1, \tau_{1}} \bar{w}_{t+1, \tau_{1}} \beta \theta \tau_{1}}{\left(\bar{s}_{t+1, \tau_{1}}-h\left(\bar{\epsilon}_{t, \tau_{0}}\right) \bar{l}_{t+1, \tau_{1}} \bar{w}_{t+1, \tau_{1}}\right)^{2}}, \\
& H_{3,1}=H_{1,3}, \quad \\
& H_{3,2}=H_{2,3}, \quad \frac{1}{H_{3,3}}=\beta \tau_{1}\left(-\frac{\bar{s}_{t+1, \tau_{1}}}{\left(\bar{l}_{t+1, \tau_{1}}-\frac{1}{h\left(\epsilon_{t+1}\right) \bar{w}_{t+1, \tau_{1}}}\right)^{2}}+\frac{B(-1+\eta) \bar{l}_{t+1, \tau_{1}}^{-2+\frac{1}{\eta}}}{\eta^{2}}\right) .
\end{aligned}
$$

The three principal minors of $H_{U}$ evaluated at the critical point $\left(\bar{\epsilon}_{t, \tau_{0}}, \bar{s}_{t+1, \tau_{1}}, \bar{l}_{t+1, \tau_{1}}\right)$ are

$$
\begin{aligned}
& H_{U, 1}=-\frac{\beta \tau_{1}}{\left(\bar{s}_{t+1, \tau_{1}}-h\left(\bar{\epsilon}_{t, \tau_{0}}\right) \bar{l}_{t+1, \tau_{1}} \bar{w}_{t+1, \tau_{1}}\right)^{2}}-\frac{\gamma \tau_{2}}{\bar{s}_{t+1, \tau_{1}}^{2}}, \\
& H_{U, 2}=\frac{B \exp \left[-2 \theta+\frac{2}{\beta \tau_{1}+\gamma \tau_{2}}\right] \theta^{2}\left(\beta \tau_{1}+\gamma \tau_{2}\right)^{4}\left(\frac{\eta\left(\beta \tau_{1}+\gamma \tau_{2}\right)}{B \beta \tau_{1}}\right)^{1-2 \eta}}{\bar{w}_{t+1, \tau_{1}}^{2} \gamma \eta \tau_{2}} \\
& H_{U, 3}=-\frac{B \exp \left[-2 \theta+\frac{2}{\beta \tau_{1}+\gamma \tau_{2}}\right] \theta^{2}\left(\beta \tau_{1}+\gamma \tau_{2}\right)^{4}\left(\frac{\eta\left(\beta \tau_{1}+\gamma \tau_{2}\right)}{B \beta \tau_{1}}\right)^{1-4 \eta}\left(\gamma \eta^{2} \tau_{2}+\beta \tau_{1}\left(\eta^{2}-(\eta-1)\left(\frac{\eta\left(\beta \tau_{1}+\gamma \tau_{2}\right)}{\beta \tau_{1}}\right)\right)\right)}{\bar{w}_{t+1, \tau_{1}}^{2} \gamma \eta^{3} \tau_{2}}
\end{aligned}
$$

It is well known that $H_{U}$ is negative definite if $H_{U, 1}<0, H_{U, 2}>0$ and $H_{U, 3}<0$. Obviously $H_{U, 1}<0, H_{U, 2}>0$ and

$$
H_{U, 3}<0 \Leftrightarrow \gamma \eta^{2} \tau_{2}+\beta \tau_{1}\left(\eta^{2}-(\eta-1)\left(\frac{\eta\left(\beta \tau_{1}+\gamma \tau_{2}\right)}{\beta \tau_{1}}\right)\right)>0 \Leftrightarrow \eta>0 .
$$


Hence, $H_{U}$ is negative definite and $U$ is locally maximized in the critical point $\left(\bar{\epsilon}_{t, \tau_{0}}, \bar{s}_{t+1, \tau_{1}}, \bar{l}_{t+1, \tau_{1}}\right)$. In addition to the interior solution, there are three possible corner solutions with $\bar{\epsilon}_{t, \tau_{0}}=$ $0, \bar{l}_{t+1, \tau_{1}}=1$ or $\bar{\epsilon}_{t, \tau_{0}}=0$ and $\bar{l}_{t+1, \tau_{1}}=1$.

i.) Let $l^{*}\left(\bar{\epsilon}_{t, \tau_{0}}\right)$ and $s^{*}\left(\bar{\epsilon}_{t, \tau_{0}}\right)$ be the locally optimal labor supply and savings for a given education level $\bar{\epsilon}_{t, \tau_{0}}$, determined by the FOC $\frac{\partial U}{\partial \bar{l}_{t+1, \tau_{1}}}=0=\frac{\partial U}{\partial \bar{s}_{t+1, \tau_{1}}}$. Therewith, the utility function reduces to $\bar{U}\left(\bar{\epsilon}_{t, \tau_{0}}\right)=U\left(\bar{\epsilon}_{t, \tau_{0}}, l^{*}\left(\bar{\epsilon}_{t, \tau_{0}}\right), s^{*}\left(\bar{\epsilon}_{t, \tau_{0}}\right)\right)$. Since $U$ is sufficiently smooth and the interior critical point is unique in $\mathbb{R} \times \mathbb{R}>0 \times \mathbb{R}$ there holds

$$
\left.\frac{\partial \bar{U}}{\partial \bar{\epsilon}_{t, \tau_{0}}}\right|_{\bar{\epsilon}_{t, \tau_{0}}=0}\left\{\begin{array}{lll}
>0 & \Rightarrow & U\left(0, l^{*}(0), s^{*}(0)\right)<U\left(\bar{\epsilon}_{t, \tau_{0}}, \bar{l}_{t+1, \tau_{1}}, \bar{s}_{t+1, \tau_{1}}\right) \\
=0 & \Rightarrow & U\left(0, l^{*}(0), s^{*}(0)\right)=U\left(\bar{\epsilon}_{t, \tau_{0}}, \bar{l}_{t+1, \tau_{1}}, \bar{s}_{t+1, \tau_{1}}\right) \\
<0 & \Rightarrow & U\left(0, l^{*}(0), s^{*}(0)\right)>U\left(\bar{\epsilon}_{t, \tau_{0}}, \bar{l}_{t+1, \tau_{1}}, \bar{s}_{t+1, \tau_{1}}\right)
\end{array}\right.
$$

Therewith, the interior solution is better than $\left(0, l^{*}(0), s^{*}(0)\right)$ if and only if

$$
\left.\frac{\partial \bar{U}}{\partial \bar{\epsilon}_{t, \tau_{0}}}\right|_{\bar{\epsilon}_{t, \tau_{0}}=0}=-1+\theta\left(\tau_{1} \beta+\tau_{2} \gamma\right)>0 \Leftrightarrow 1-\frac{1}{\theta\left(\tau_{1} \beta+\tau_{2} \gamma\right)}>0 .
$$

ii.) Let $\bar{l}_{t+1, \tau_{1}}=1$, then analogously to above there holds that the interior solution is better than $\left(\epsilon^{*}(1), 1, s^{*}(1)\right)$ if and only if

$$
\left.\frac{\partial \hat{U}}{\partial \bar{l}_{t+1, \tau_{1}}}\right|_{\bar{l}_{t+1, \tau_{1}}=1}=\frac{-B \tau_{1} \beta+\tau_{1} \beta \eta+\tau_{2} \gamma \eta}{\eta}<0 \quad \Leftrightarrow \quad \frac{\tau_{1} \beta+\tau_{2} \gamma}{B \beta \tau_{1} \frac{1}{\eta}}<1
$$

with $\hat{U}\left(\bar{l}_{t+1, \tau_{1}}\right):=U\left(\epsilon^{*}\left(\bar{l}_{t+1, \tau_{1}}\right), \bar{l}_{t+1, \tau_{1}}, s^{*}\left(\bar{l}_{t+1, \tau_{1}}\right)\right)$.

iii.) Finally, let $\bar{\epsilon}_{t, \tau_{0}}=0$ and $\bar{l}_{t+1, \tau_{1}}=1$. Then, analogously to above

$$
\begin{aligned}
& \left.\frac{\partial \widetilde{U}}{\partial \bar{l}_{t+1, \tau_{1}}}\right|_{\bar{\epsilon}_{t, \tau_{0}}=0, \bar{l}_{t+1, \tau_{1}}=1}<0 \quad \Leftrightarrow \quad 1-\frac{1}{\theta\left(\tau_{1} \beta+\tau_{2} \gamma\right)}>0 \\
& \left.\frac{\partial \widetilde{U}}{\partial \bar{\epsilon}_{t, \tau_{0}}}\right|_{\bar{\epsilon}_{t, \tau_{0}}=0, \bar{l}_{t+1, \tau_{1}}=1}>0 \quad \Leftrightarrow \quad \frac{\tau_{1} \beta+\tau_{2} \gamma}{B \beta \tau_{1} \frac{1}{\eta}}<1
\end{aligned}
$$

which leads to $U\left(0,1, s^{*}(0,1)\right)<U\left(\bar{\epsilon}_{t, \tau_{0}}, \bar{l}_{t+1, \tau_{1}}, \bar{s}_{t+1, \tau_{1}}\right)$, with

$$
\widetilde{U}\left(\bar{\epsilon}_{t, \tau_{0}}, \bar{l}_{t+1, \tau_{1}}\right):=U\left(\bar{\epsilon}_{t, \tau_{0}}, \bar{l}_{t+1, \tau_{1}}, s^{*}\left(\bar{\epsilon}_{t, \tau_{0}}, \bar{l}_{t+1, \tau_{1}}\right)\right) \text {. }
$$

Furthermore, the interior solution lies in the interior of the feasible set iff (A.9) and (A.10) are both satisfied. In that case it is also globally optimal. Moreover, since $U$ is sufficiently smooth and there exists exactly one interior solution in $\mathbb{R} \times \mathbb{R}_{>0} \times \mathbb{R}, U$ is monotonically, but not necessarily strictly monotonically, decreasing in $\bar{\epsilon}_{t, \tau_{0}} \in[0,1)$ if (A.9) is not satisfied, and abalogously, $U$ is monotonically increasing in $\bar{l}_{t+1, \tau_{1}} \in(0,1]$ if (A.10) is not satisfied. Therewith, the globally optimal solution is

$$
\begin{aligned}
\bar{\epsilon}_{t, \tau_{0}} & =\max \left\{0,1-\frac{1}{\theta\left(\beta \tau_{1}+\gamma \tau_{2}\right)}\right\} \\
\bar{l}_{t+1, \tau_{1}} & =\min \left\{1,\left(\frac{B(a)}{\eta}\right)^{-\eta} \cdot\left(\frac{\beta \tau_{1}}{\beta \tau_{1}+\gamma \tau_{2}}\right)^{-\eta}\right\} \\
\bar{s}_{t+1, \tau_{1}} & =\frac{\gamma \tau_{2} h\left(\bar{\epsilon}_{t, \tau_{0}}\right) \bar{l}_{t+1, \tau_{1}}}{\beta \tau_{1}+\gamma \tau_{2}} \cdot \bar{w}_{t+1, \tau_{1}} .
\end{aligned}
$$




\section{Appendix B. Proof of the Propositions}

In the following proofs only the interior solution is considered.

Proof of Proposition 1. The partial derivatives of the optimal value $\bar{\epsilon}_{t, \tau_{0}}$, c.f. (A.5), are

$$
\begin{aligned}
\frac{\partial \bar{\epsilon}_{t, \tau_{0}}}{\partial \tau_{1}} & =\frac{\beta}{\theta\left(\beta \tau_{1}+\gamma \tau_{2}\right)^{2}}>0 \\
\frac{\partial \bar{\epsilon}_{t, \tau_{0}}}{\partial \tau_{2}} & =\frac{\gamma}{\theta\left(\beta \tau_{1}+\gamma \tau_{2}\right)}>0 \\
\frac{\partial \bar{\epsilon}_{t, \tau_{0}}}{\partial \theta} & =\frac{1}{\theta^{2}\left(\beta \tau_{1}+\gamma \tau_{2}\right)}>0 .
\end{aligned}
$$

Proof of Proposition 2. The partial derivatives of the optimal value $\bar{l}_{t+1, \tau_{1}}$, c.f. (A.6), with respect to $\tau_{1}, \tau_{2}$ are

$$
\begin{aligned}
\frac{\partial \bar{l}_{t+1, \tau_{1}}}{\partial \tau_{1}}=-\frac{B \beta \gamma \tau_{2}\left(\frac{\eta\left(\beta \tau_{1}+\gamma \tau_{2}\right)}{B \beta \tau_{1}}\right)^{1+\eta}}{\left(\beta \tau_{1}+\gamma \tau_{2}\right)^{2}} & <0 \\
\frac{\partial \bar{l}_{t+1, \tau_{1}}}{\partial \tau_{2}}=\frac{\eta \gamma\left(\frac{\beta \tau_{1}+\gamma \tau_{2}}{B \beta \tau_{1}}\right)^{\eta}}{\beta \tau_{1}+\gamma \tau_{2}} & >0
\end{aligned}
$$

Proof of Proposition 3. The partial derivative of the interior solution of the aggregate labor supply $L_{t+1, \tau_{1}}$ with respect to $\tau_{1}$ is

$$
\frac{\partial L_{t+1, \tau_{1}}}{\partial \tau_{1}}=\frac{\left(\frac{\eta\left(\beta \tau_{1}+\gamma \tau_{2}\right)}{B \beta \tau_{1}}\right)^{\eta}\left(\beta \tau_{1}-\gamma(-1+\eta) \tau_{2}\right)}{\left(\beta \tau_{1}+\gamma \tau_{2}\right)}
$$

This leads to

$$
\frac{\partial L_{t+1, \tau_{1}}}{\partial \tau_{1}}<0 \Leftrightarrow \beta \tau_{1}-\gamma(-1+\eta) \tau_{2}<0 \Leftrightarrow \eta>\frac{\beta \tau_{1}+\gamma \tau_{2}}{\gamma \tau_{2}}
$$

Proof of Proposition 4. The first order condition for a minimum is

$$
\begin{gathered}
\frac{\partial L_{t+1, \tau_{1}}}{\partial \tau_{1}}=\frac{\left(\frac{\eta\left(\beta \tau_{1}+\gamma \tau_{2}\right)}{B \beta \tau_{1}}\right)^{\eta}\left(\beta \tau_{1}-\gamma(-1+\eta) \tau_{2}\right)}{\left(\beta \tau_{1}+\gamma \tau_{2}\right)} \stackrel{!}{=} 0 \\
\Leftrightarrow \quad \beta \tau_{1}-\gamma(-1+\eta) \tau_{2}=0 \\
\Leftrightarrow \tau_{1}^{\text {min }}=\frac{(\eta-1) \gamma \tau_{2}}{\beta} .
\end{gathered}
$$

Since

$$
\frac{\partial^{2} L_{t+1, \tau_{1}}}{\partial \tau_{1}^{2}} \mid \tau_{1}^{\min }=\frac{\beta\left(\frac{\eta^{2}}{B(\eta-1)}\right)^{\eta}}{\gamma \eta \tau_{2}}>0 \quad \text { for } \quad \eta>1
$$

$\tau_{1}^{\text {min }}$ is a minimum. 
Proof of Proposition 5. The partial derivatives of $\tilde{s}_{t+1, \tau_{1}}$, c.f. (A.7), with resprect to $\tau_{1}, \tau_{2}$ and $\theta$ are

$$
\begin{array}{rlrl}
\frac{\partial \tilde{s}_{t+1, \tau_{1}}}{\partial \tau_{2}} & =\frac{h\left(\bar{\epsilon}_{t, \tau_{0}}\right) \cdot l \cdot \gamma\left(\gamma \tau_{2}+\left(\beta \tau_{1}+\gamma \tau_{2}\right)\left(\beta \tau_{1}+\gamma \eta \tau_{2}\right)\right)}{\tau_{1}\left(\beta \tau_{1}+\gamma \eta \tau_{2}\right)^{3}} & >0 \\
\frac{\partial \tilde{s}_{t+1, \tau_{1}}}{\partial \theta}=\frac{h\left(\bar{\epsilon}_{t, \tau_{0}}\right) \cdot l \cdot \gamma \tau_{2}}{\beta \tau_{1}+\gamma \tau_{2}} & >0 \\
\frac{\partial \tilde{s}_{t+1, \tau_{1}}}{\partial \tau_{1}} & =-\frac{h\left(\bar{\epsilon}_{t, \tau_{0}}\right) \cdot l \cdot \gamma \tau_{2}\left(\beta \tau_{1}\left(-1+\beta \tau_{1}\right)+\beta \gamma(1+\eta) \tau_{1} \tau_{2}+\gamma^{2} \eta \tau_{2}^{2}\right)}{\tau_{1}\left(\beta \tau_{1}+\gamma \tau_{2}\right)^{3}}
\end{array}
$$

The sign of the derivative $\frac{\partial \tilde{s}_{t+1, \tau_{1}}}{\partial \tau_{1}}$ is negative if and only if

$$
\begin{gathered}
\beta \tau_{1}\left(-1+\beta \tau_{1}\right)+\beta \gamma(1+\eta) \tau_{1} \tau_{2}+\gamma^{2} \eta \tau_{2}^{2}>0 \\
\Leftrightarrow \eta>\frac{\beta \tau_{1}\left(1-\beta \tau_{1}-\gamma \tau_{2}\right)}{\gamma \tau_{2}\left(\beta \tau_{1}+\gamma \tau_{2}\right)} .
\end{gathered}
$$

The partial derivative of the aggregate savings rate $\widetilde{S}_{t+1, \tau_{1}}$ with respect to the period length $\tau_{1}$ is

$$
\frac{\partial \widetilde{S}_{t+1, \tau_{1}}}{\partial \tau_{1}}=-\frac{h\left(\bar{\epsilon}_{t, \tau_{0}}\right) \cdot l \cdot \gamma \tau_{2}\left(\gamma^{2}(-1+\eta) \tau_{2}^{2}+\beta \tau_{1}\left(-1+\gamma(-1+\eta) \tau_{2}\right)\right)}{\left(\beta \tau_{1}+\gamma \tau_{2}\right)^{3}} .
$$

The sign of this derivative is positive if and only if

$$
\begin{gathered}
\gamma^{2}(-1+\eta) \tau_{2}^{2}+\beta \tau_{1}\left(-1+\gamma(-1+\eta) \tau_{2}\right)<0 \\
\Leftrightarrow \eta<\frac{\beta \tau_{1}+\beta \gamma \tau_{1} \tau_{2}+\gamma^{2} \tau_{2}^{2}}{\beta \gamma \tau_{1} \tau_{2}+\gamma^{2} \tau_{2}^{2}} .
\end{gathered}
$$




\section{REFERENCES}

Acemoglu, D., Johnson, S., 2007, Disease and development: The effect of life expectancy on economic growth, Journal of Political Economy 115, 925-985.

Arking, R., 2006, The Biology of Aging: Observations and Principles, Oxford University Press, Oxford.

Baltes, PB and Smith, J., 2003, New frontiers in the future of aging: from successful aging of the young old to the dilemmas of the fourth age, Gerontology 49, 123-135.

Becker, G.S., 1962, Investment in human capital: a theoretical analysis, Journal of Political Economy 70, 9-49.

Ben-Porath, Y., 1967, The production of human capital and the life cycle of earnings, Journal of Political Economy 75, 352-365.

Bils, M. and Klenow, P.J., 2000, Does schooling cause growth?,American Economic Review 90, 1160-1183.

Birchenall, J.A., 2007, Escaping high mortality, Journal of Economic Growth 12, 351-387.

Bleakley, H., 2011, Health, human capital, and development, Annual Reviews of Economics 2, $283-310$

Boucekinne, R, de la Croix, D., and Licandro, O., 2002, Vintage human capital, demographic trends, and endogenous growth, Journal of Economic Theory 104, 340.375.

Boucekinne, R, de la Croix, D., and Licandro, O., 2003, Early mortality declines at the dawn of modern growth, Scandinavian Journal of Economics 105, 401-418.

Byham, W.C., 2007, 70: The New 50 - Retirement Management: Retaining the Energy and Expertise of Experienced Employees, Development Dimensions International.

Card, D., 1999, The causal effect of education on earnings, Handbook of Labor Economics Vol. 3, 1801-1863, Elsevier, Amsterdam.

Cervellati, M. and U. Sunde, 2005, Human capital formation, life expectancy, and the process of development, American Economic Review 95, 1653-1672.

Cervellati, M. and Sunde, U., 2010, Longevity and lifetime labor supply: evidence and implications revisited, Discussion Paper.

Cervellati, M. and U. Sunde, 2011a, Human capital, mortality and fertility: A unified theory of the economic and demographic transition, Discussion Paper.

Cervellati, M. and U. Sunde, 2011b, Life expectancy and economic growth: the role of the demographic transition, Journal of Economic Growth 16, 99-133.

Chakraborty, S., 2004, Endogenous lifetime and economic growth, Journal of Economic Theory $116,119-137$. 
Clark, G., 2007, A Farewell to Alms, Princeton University Press, Princeton.

Crafts, N. F. R., 1985, British Economic Growth During the Industrial Revolution, Oxford University Press, Oxford.

Crafts, N.F.R. and Harley, C.K, 1992, Output growth and the British Industrial Revolution: A Restatement of the Crafts-Harley view, Economic History Review 45, 703-730

Cutler, D.M., Lleras-Muney, A. and Vogl, T., 2011, Socioeconomic status and health: dimensions and mechanisms, in: Glied, S. and Smith, P.C. (eds), The Oxford Handbook of Health Economics, Oxford University Press, Oxford, pp. 124-163.

d'Albis, H., Lau, S.P., and Sánchez-Romero, M., 2012, Mortality transition and differential incentives for early retirement, Journal of Economic Theory 147, 261-283.

de la Croix, D., and Licandro, O., 1999, Life expectancy and endogenous growth, Economics Letters 65, 255-263.

Fries, J.F., 1980, Aging, natural death, and the compression of morbidity, New England Journal of Medicine 303, 130-135.

Galor, O. and Weil, D.N., 2000, Population, technology and growth: from Malthusian stagnation to the demographic transition and beyond, American Economic Review 76, 807-828.

Galor, O., 2005, From stagnation to growth: unified growth theory, in: P. Aghion and S. Durlauf, Handbook of Economic Growth Vol 1A, Amsterdam, North-Holland.

Galor, O., 2011, Unified growth theory, Princeton University Press.

Gavrilov, L.A. and Gavrilova, N.S., 1991, The Biology of Human Life Span: A Quantitative Approach, Harwood Academic Publishers, London.

Gordon, R., 1999, U.S. economic growth since 1870: One big wave? American Economic Review 89, 123-128.

Hansen, C.W. and Lønstrup, L., 2012, Can higher life expectancy induce more schooling and earlier retirement?, Journal of Population Economics, 25(4), 1249-1264.

Hazan, M., 2009, Longevity and lifetime labor supply: Evidence and implications, Econometrica $77,1829-1863$.

Hazan, M., and Zoabi, H., 2006, Does longevity cause growth? A theoretical critique, Journal of Economic Growth 11, 363-76.

Jayachandran, S., and Lleras-Muney, A., 2009, Life expectancy and human capital investments: Evidence from maternal mortality declines, Quarterly Journal of Economics 124, 349-397.

Kalemli-Ozcan, S., Ryder, H. E., and Weil, D. N., 2000, Mortality decline, human capital investment, and economic growth, Journal of Development Economics 62, 1-23.

Kalemli-Ozcan, S., Weil, D.N., 2010, Mortality change, the uncertainty effect, and retirement, Journal of Economic Growth 15, 65-91. 
Krueger, A.B. and Lindahl, M., 2001, Education for growth: why and for whom?, Journal of Economic Literature, 39, 1101-1136.

Lorentzen P., McMillan, J., and Wacziarg, R., 2008, Death and development, Journal of Economic Growth 13, 81-124.

Maddison, A., 1992, A long-run perspective on saving,Scandinavian Journal of Economics 94, 181-196.

Maddison, A., 2003, The World Economy: Historical Statistics, Development Center Studies, OECD, Paris.

Manton, K.G., Gu, X.L., and Lamb, V.L., 2006, Long-term trends in life expectancy and active life expectancy in the United States, Population and Development Review 32, 81-105.

Mincer, J., 1974, Schooling, Experience and Earnings, Columbia University Press, New York.

Mitnitski, A.B. and Mogilner, A.J. and MacKnight, C. and Rockwood, K., 2002, The accumulation of deficits with age and possible invariants of aging, Scientific World 2, 18161822.

Mitnitski, A. and Song, X. and Skoog, I. and Broe, GA and Cox, J.L. and Grunfeld, E. and Rockwood, K., 2005, Relative fitness and frailty of elderly men and women in developed countries and their relationship with mortality, Journal of the American Geriatrics Society $53,2184-2189$.

Mitnitski, A. and Bao, L. and Rockwood, K., 2006, Going from bad to worse: a stochastic model of transitions in deficit accumulation, in relation to mortality, Mechanisms of Ageing and Development 127, 490-493.

Olshansky, S.J. and Carnes, B.A., 1997, Ever since Gompertz, Demography 34, 1-15.

Prescott, Edward C., 1986, Theory ahead of business cycle measurement, Carnegie Rochester Conference Series on Public Policy 25, 11-66.

Preston, S.H., 1975, The changing relation between mortality and level of economic development, Population Studies 29, 231-248.

Psacharopoulos, G. and Patrinos, H.A., 2004, Returns to investment in education: a further update, Education Economics 12, 111-134.

Ramey, V,A., Francis, N., 2009, A century of work and leisure, American Economic Journal: Macroeconomics 1, 189-224.

Rice, D.P., Fineman, 2004, Economic implications of increased longevity in the United States, Annual Review of Public Health 25, 457-473.

Soares, R., 2005, Mortality reductions, educational attainment, and fertility choice, American Economic Review 95, 580-601.

Sheshinski, E., 2009, Uncertain longevity and investment in education, Working Paper, Hebrew University. 
Skirbekk, V., Loichinger, E., and Weber, D., 2012, Variation in cognitive functioning as a refined approach to comparing aging across countries, Proceedings of the National Academy of Sciences 109, 770-774.

Tamura, R., 2006, Human capital and economic development, Journal of Development Economics $79,26-72$.

Turner, C., Tamura, R., Mulholland, S.E., Baier, S., 2007, Education and income of the States of the United States: 1840-2000, Journal of Economic Growth 12, 101-158.

Weil, D., 2007, Accounting for the effect of health on economic growth, Quarterly Journal of Economics 122, 1265-1306.

WHO (2012), Global Health Observatory Data Repository, http://apps . who.int/ghodata/

Zhang, J., Zhang, J., and Lee, R., 2003, Rising longevity, education, savings, and growth, Journal of Development of Economics 70, 83-101. 


\section{Bisher erschienene Diskussionspapiere}

Nr. 141: Strulik, Holger, Werner, Katharina: Life Expectancy, Labor Supply, and Long-Run Growth: Reconciling Theory and Evidence, September 2012

Nr. 140: Strulik, Holger, Prettner, Klaus; Prskawetz, Alexia: The Past and Future of Knowledgebased Growth, September 2012

Nr. 139: Prettner, Klaus; Trimborn, Timo: Demographic change and R\&D-based economic growth: reconciling theory and evidence, September 2012

Nr. 138: König, Jörg; Ohr, Renate: Homogeneous groups within a heterogeneous community Evidence from an index measuring European economic integration, August 2012

Nr. 137: Schwager, Robert: Student Loans in a Tiebout Model of Higher, July 2012

Nr. 136: Martínez-Zarzoso, Inmaculada: Exporting and Productivity: Evidence for Egypt and Morocco, April 2012

Nr. 135: König, Jörg; Ohr, Renate: Messung ökonomischer Integration in der Europäischen Union Entwicklung eines EU-Integrationsindexes -, April 2012

Nr. 134: Gehringer, Agnieszka: Financial liberalization, growth, productivity and capital accumulation: The case of European integration, März 2012

Nr. 133: Berner, Eike; Birg, Laura: Retailers and Consumers. The pass-through of import price changes, März 2012

Nr. 132: Gehringer, Angnieszka: Current accounts in Europe: implications of the external imbalances for the future of the common monetary policy, März 2012

Nr. 131: Ohr, Renate; Özalbayrak, Mehmet: The Euro - A „MUST“ for Small European States?, Januar 2012

Nr. 130: Zeddies, Götz: Der Euro als Triebfeder des deutschen Exports?, November 2011

Nr. 129: Geishecker, Ingo; Siedler, Thomas: Job Loss Fears and (Extreme) Party Identification: First Evidence from Panel Data, Oktober 2011

Nr. 128: König, Jörg; Ohr, Renate: Small but Beautiful? Economic Impacts of the Size of Nations in the European Union, August 2011

Nr. 127: Schüder, Stefan: Monetary Policy Trade-Offs in a Portfolio Model with Endogenous Asset Supply, Juni 2011

Nr. 126: Hiller, Sanne: The Export Promoting Effect of Emigration: Evidence from Denmark, Juni 2011

Nr. 125: Martínez-Zarzoso, Inmaculada; Voicu, Anca M.; Vidovic, Martina: CEECs Integration into Regional and Global Production Networks, Mai 2011

Nr. 124: Roth, Felix; Gros, Daniel; Nowak-Lehmann D., Felicitas: Has the Financial Crisis eroded Citizens' Trust in the European Central Bank? Panel Data Evidence for the Euro Area, 1999-2011, Mai 2011, Revised Version März 2012

Nr. 123 Dreher, Axel; Vreeland, James Raymond : Buying Votes and International Organizations, Mai 2011

Nr. 122: Schürenberg-Frosch, Hannah: One Model fits all? Determinants of Transport Costs across Sectors and Country Groups, April 2011

Nr. 121: Verheyen, Florian: Bilateral Exports from Euro Zone Countries to the US - Does Exchange Rate Variability Play a Role?, April 2011

Nr. 120: Ehlers, Tim: University Graduation Dependent on Family's Wealth, Ability and Social Status, April 2011 
Nr. 119: Cho, Seo-Young; Dreher, Axel; Neumayer, Eric: The Spread of Anti-trafficking Policies Evidence from a New Index, März 2011

Nr. 118: Cho, Seo-Young; Vadlamannati, Krishna Chaitanya: Compliance for Big Brothers: An Empirical Analysis on the Impact of the Anti-trafficking Protocol, Februar 2011

Nr. 117: Nunnenkamp, Peter; Öhler, Hannes: Donations to US based NGOs in International Development Cooperation: How (Un-)Informed Are Private Donors?, Februar 2011

Nr. 116: Geishecker, Ingo; Riedl, Maximilian: Ordered Response Models and Non-Random Personality Traits: Monte Carlo Simulations and a Practical Guide, Revised Version Februar 2012

Nr. 115: Dreher, Axel; Gassebner, Martin; Siemers, Lars-H. R.: Globalization, Economic Freedom and Human Rights, Oktober 2010

Nr. 114: Dreher, Axel; Mikosch, Heiner; Voigt, Stefan: Membership has its Privileges - The Effect of Membership in International Organizations on FDI, Oktober 2010

Nr. 113: Fuchs, Andreas; Klann, Nils-Hendrik: Paying a Visit: The Dalai Lama Effect on International Trade, Oktober 2010

Nr. 112: Freitag, Stephan: Choosing an Anchor Currency for the Pacific, Oktober 2010

Nr. 111: Nunnenkamp, Peter; Öhler, Hannes: Throwing Foreign Aid at HIV/AIDS in Developing Countries: Missing the Target?, August 2010

Nr. 110: Ohr, Renate; Zeddies, Götz: „Geschäftsmodell Deutschland“ und außenwirtschaftliche Ungleichgewichte in der EU, Juli 2010

Nr. 109: Nunnenkamp, Peter; Öhler, Hannes: Funding, Competition and the Efficiency of NGOs: An Empirical Analysis of Non-charitable Expenditure of US NGOs Engaged in Foreign Aid, Juli 2010

Nr. 108: Krenz, Astrid: La Distinction reloaded: Returns to Education, Family Background, Cultural and Social Capital in Germany, Juli 2010

Nr. 107: Krenz, Astrid: Services sectors' agglomeration and its interdependence with industrial agglomeration in the European Union, Juli 2010

Nr. 106: Krenz, Astrid; Rübel, Gerhard: Industrial Localization and Countries' Specialization in the European Union: An Empirical Investigation, Juli 2010

Nr. 105: Schinke, Jan Christian: Follow the Sun! How investments in solar power plants in Sicily can generate high returns of investments and help to prevent global warming, Juni 2010

Nr. 104: Dreher, Axel; Sturm, Jan-Egbert; Vreeland, James Raymon: Does membership on the Security Council influence IMF conditionality?, Juni 2010

Nr. 103: Öhler, Hannes; Nunnenkamp, Peter; Dreher, Axel: Does Conditionality Work? A Test for an Innovative US Aid Scheme, Juni 2010

Nr. 102: Gehringer, Agnieszka: Pecuniary Knowledge Externalities in a New Taxonomy: Knowledge Interactions in a Vertically Integrated System, Juni 2010

Nr. 101: Gehringer, Agnieszka: Pecuniary Knowledge Externalities across European Countries - are there leading Sectors?, Juni 2010

Nr. 100: Gehringer, Agnieszka: Pecuniary Knowledge Externalities and Innovation: Intersectoral Linkages and their Effects beyond Technological Spillovers, Juni 2010

Nr. 99: Dreher, Axel; Nunnenkamp, Peter; Öhler, Hannes: Why it pays for aid recipients to take note of the Millennium Challenge Corporation: Other donors do!, April 2010

Nr. 98: Baumgarten, Daniel; Geishecker, Ingo; Görg, Holger: Offshoring, tasks, and the skill-wage pattern, März 2010

Nr. 97: Dreher, Axel; Klasen, Stephan; Raymond, James; Werker, Eric: The costs of favoritism: Is politically-driven aid less effective?, März 2010 
Nr. 96: Dreher, Axel; Nunnenkamp, Peter; Thiele, Rainer: Are 'New' Donors Different? Comparing the Allocation of Bilateral Aid between Non-DAC and DAC Donor Countries, März 2010

Nr. 95: Lurweg, Maren; Westermeier, Andreas: Jobs Gained and Lost through Trade - The Case of Germany, März 2010

Nr. 94: Bernauer, Thomas; Kalbhenn, Anna; Koubi, Vally; Ruoff, Gabi: On Commitment Levels and Compliance Mechanisms - Determinants of Participation in Global Environmental Agreements, Januar 2010

Nr. 93: Cho, Seo-Young: International Human Rights Treaty to Change Social Patterns - The Convention on the Elimination of All Forms of Discrimination against Women, Januar 2010

Nr. 92: Dreher, Axel; Nunnenkamp, Peter; Thiel, Susann; Thiele, Rainer: Aid Allocation by German NGOs: Does the Degree of Public Refinancing Matter?, Januar 2010

Nr. 91: Bjørnskov, Christian; Dreher, Axel; Fischer, Justina A. V.; Schnellenbach, Jan: On the relation between income inequality and happiness: Do fairness perceptions matter?, Dezember 2009

Nr. 90: Geishecker, Ingo: Perceived Job Insecurity and Well-Being Revisited: Towards Conceptual Clarity, Dezember 2009

Nr. 89: Kühl, Michael: Excess Comovements between the Euro/US dollar and British pound/US dollar exchange rates, November 2009

Nr. 88: Mourmouras, Alex, Russel, Steven H.: Financial Crises, Capital Liquidation and the Demand for International Reserves, November 2009

Nr. 87: Goerke, Laszlo, Pannenberg, Markus: An Analysis of Dismissal Legislation: Determinants of Severance Pay in West Germany, November 2009

Nr. 86: Marchesi, Silvia, Sabani, Laura, Dreher, Axel: Read my lips: the role of information transmission in multilateral reform design, Juni 2009

Nr. 85: Heinig, Hans Michael: Sind Referenden eine Antwort auf das Demokratiedilemma der EU?, Juni 2009

Nr. 84: El-Shagi, Makram: The Impact of Fixed Exchange Rates on Fiscal Discipline, Juni 2009

Nr. 83: Schneider, Friedrich: Is a Federal European Constitution for an Enlarged European Union Necessary? Some Preliminary Suggestions using Public Choice Analysis, Mai 2009

Nr. 82: Vaubel, Roland: Nie sollst Du mich befragen? Weshalb Referenden in bestimmten Politikbereichen - auch in der Europapolitik - möglich sein sollten, Mai 2009

Nr. 81: Williamson, Jeffrey G.: History without Evidence: Latin American Inequality since 1491, Mai 2009

Nr. 80: Erdogan, Burcu: How does the European Integration affect the European Stock Markets?, April 2009

Nr. 79: Oelgemöller, Jens; Westermeier, Andreas: RCAs within Western Europe, März 2009

Nr. 78: Blonski, Matthias; Lilienfeld-Toal, Ulf von: Excess Returns and the Distinguished Player Paradox, Oktober 2008

Nr. 77: Lechner, Susanne; Ohr, Renate: The Right of Withdrawal in the Treaty of Lisbon: A game theoretic reflection on different decision processes in the EU, Oktober 2008

Nr. 76: Kühl, Michael: Strong comovements of exchange rates: Theoretical and empirical cases when currencies become the same asset, Juli 2008

Nr. 75: Höhenberger, Nicole; Schmiedeberg, Claudia: Structural Convergence of European Countries, Juli 2008

Nr. 74: Nowak-Lehmann D., Felicitas; Vollmer, Sebastian; Martinez-Zarzoso, Inmaculada: Does Comparative Advantage Make Countries Competitive? A Comparison of China and Mexico, Juli 2008 
Nr. 73: Fendel, Ralf; Lis, Eliza M.; Rülke, Jan-Christoph: Does the Financial Market Believe in the Phillips Curve? - Evidence from the G7 countries, Mai 2008

Nr. 72: Hafner, Kurt A.: Agglomeration Economies and Clustering - Evidence from German Firms, Mai 2008

Nr. 71: Pegels, Anna: Die Rolle des Humankapitals bei der Technologieübertragung in Entwicklungsländer, April 2008

Nr. 70: Grimm, Michael; Klasen, Stephan: Geography vs. Institutions at the Village Level, Februar 2008

Nr. 69: Van der Berg, Servaas: How effective are poor schools? Poverty and educational outcomes in South Africa, Januar 2008

Nr. 68: Kühl, Michael: Cointegration in the Foreign Exchange Market and Market Efficiency since the Introduction of the Euro: Evidence based on bivariate Cointegration Analyses, Oktober 2007

Nr. 67: Hess, Sebastian; Cramon-Taubadel, Stephan von: Assessing General and Partial Equilibrium Simulations of Doha Round Outcomes using Meta-Analysis, August 2007

Nr. 66: Eckel, Carsten: International Trade and Retailing: Diversity versus Accessibility and the Creation of "Retail Deserts", August 2007

Nr. 65: Stoschek, Barbara: The Political Economy of Enviromental Regulations and Industry Compensation, Juni 2007

Nr. 64: Martinez-Zarzoso, Inmaculada; Nowak-Lehmann D., Felicitas; Vollmer, Sebastian: The Log of Gravity Revisited, Juni 2007

Nr. 63: Gundel, Sebastian: Declining Export Prices due to Increased Competition from NIC Evidence from Germany and the CEEC, April 2007

Nr. 62: Wilckens, Sebastian: Should WTO Dispute Settlement Be Subsidized?, April 2007

Nr. 61: Schöller, Deborah: Service Offshoring: A Challenge for Employment? Evidence from Germany, April 2007

Nr. 60: Janeba, Eckhard: Exports, Unemployment and the Welfare State, März 2007

Nr. 59: Lambsdoff, Johann Graf; Nell, Mathias: Fighting Corruption with Asymmetric Penalties and Leniency, Februar 2007

Nr. 58: Köller, Mareike: Unterschiedliche Direktinvestitionen in Irland - Eine theoriegestützte Analyse, August 2006

Nr. 57: Entorf, Horst; Lauk, Martina: Peer Effects, Social Multipliers and Migrants at School: An International Comparison, März 2007 (revidierte Fassung von Juli 2006)

Nr. 56: Görlich, Dennis; Trebesch, Christoph: Mass Migration and Seasonality Evidence on Moldova's Labour Exodus, Mai 2006

Nr. 55: Brandmeier, Michael: Reasons for Real Appreciation in Central Europe, Mai 2006

Nr. 54: Martínez-Zarzoso, Inmaculada; Nowak-Lehmann D., Felicitas: Is Distance a Good Proxy for Transport Costs? The Case of Competing Transport Modes, Mai 2006

Nr. 53: Ahrens, Joachim; Ohr, Renate; Zeddies, Götz: Enhanced Cooperation in an Enlarged EU, April 2006

Nr. 52: Stöwhase, Sven: Discrete Investment and Tax Competition when Firms shift Profits, April 2006

Nr. 51: Pelzer, Gesa: Darstellung der Beschäftigungseffekte von Exporten anhand einer InputOutput-Analyse, April 2006

Nr. 50: Elschner, Christina; Schwager, Robert: A Simulation Method to Measure the Tax Burden on Highly Skilled Manpower, März 2006 
Nr. 49: Gaertner, Wulf; Xu, Yongsheng: A New Measure of the Standard of Living Based on Functionings, Oktober 2005

Nr. 48: Rincke, Johannes; Schwager, Robert: Skills, Social Mobility, and the Support for the Welfare State, September 2005

Nr. 47: Bose, Niloy; Neumann, Rebecca: Explaining the Trend and the Diversity in the Evolution of the Stock Market, Juli 2005

Nr. 46: Kleinert, Jörn; Toubal, Farid: Gravity for FDI, Juni 2005

Nr. 45: Eckel, Carsten: International Trade, Flexible Manufacturing and Outsourcing, Mai 2005

Nr. 44: Hafner, Kurt A.: International Patent Pattern and Technology Diffusion, Mai 2005

Nr. 43: Nowak-Lehmann D., Felicitas; Herzer, Dierk; Martínez-Zarzoso, Inmaculada; Vollmer, Sebastian: Turkey and the Ankara Treaty of 1963: What can Trade Integration Do for Turkish Exports, Mai 2005

Nr. 42: Südekum, Jens: Does the Home Market Effect Arise in a Three-Country Model?, April 2005

Nr. 41: Carlberg, Michael: International Monetary Policy Coordination, April 2005

Nr. 40: Herzog, Bodo: Why do bigger countries have more problems with the Stability and Growth Pact?, April 2005

Nr. 39: Marouani, Mohamed A.: The Impact of the Mulitfiber Agreement Phaseout on Unemployment in Tunisia: a Prospective Dynamic Analysis, Januar 2005

Nr. 38: Bauer, Philipp; Riphahn, Regina T.: Heterogeneity in the Intergenerational Transmission of Educational Attainment: Evidence from Switzerland on Natives and Second Generation Immigrants, Januar 2005

Nr. 37: Büttner, Thiess: The Incentive Effect of Fiscal Equalization Transfers on Tax Policy, Januar 2005

Nr. 36: Feuerstein, Switgard; Grimm, Oliver: On the Credibility of Currency Boards, Oktober 2004

Nr. 35: Michaelis, Jochen; Minich, Heike: Inflationsdifferenzen im Euroraum - eine Bestandsaufnahme, Oktober 2004

Nr. 34: Neary, J. Peter: Cross-Border Mergers as Instruments of Comparative Advantage, Juli 2004

Nr. 33: Bjorvatn, Kjetil; Cappelen, Alexander W.: Globalisation, inequality and redistribution, Juli 2004

Nr. 32: Stremmel, Dennis: Geistige Eigentumsrechte im Welthandel: Stellt das TRIPs-Abkommen ein Protektionsinstrument der Industrieländer dar?, Juli 2004

Nr. 31: Hafner, Kurt: Industrial Agglomeration and Economic Development, Juni 2004

Nr. 30: Martinez-Zarzoso, Inmaculada; Nowak-Lehmann D., Felicitas: MERCOSUR-European Union Trade: How Important is EU Trade Liberalisation for MERCOSUR's Exports?, Juni 2004

Nr. 29: Birk, Angela; Michaelis, Jochen: Employment- and Growth Effects of Tax Reforms, Juni 2004

Nr. 28: Broll, Udo; Hansen, Sabine: Labour Demand and Exchange Rate Volatility, Juni 2004

Nr. 27: Bofinger, Peter; Mayer, Eric: Monetary and Fiscal Policy Interaction in the Euro Area with different assumptions on the Phillips curve, Juni 2004

Nr. 26: Torlak, Elvisa: Foreign Direct Investment, Technology Transfer and Productivity Growth in Transition Countries, Juni 2004

Nr. 25: Lorz, Oliver; Willmann, Gerald: On the Endogenous Allocation of Decision Powers in Federal Structures, Juni 2004

Nr. 24: Felbermayr, Gabriel J.: Specialization on a Technologically Stagnant Sector Need Not Be Bad for Growth, Juni 2004 
Nr. 23: Carlberg, Michael: Monetary and Fiscal Policy Interactions in the Euro Area, Juni 2004

Nr. 22: Stähler, Frank: Market Entry and Foreign Direct Investment, Januar 2004

Nr. 21: Bester, Helmut; Konrad, Kai A.: Easy Targets and the Timing of Conflict, Dezember 2003

Nr. 20: Eckel, Carsten: Does globalization lead to specialization, November 2003

Nr. 19: Ohr, Renate; Schmidt, André: Der Stabilitäts- und Wachstumspakt im Zielkonflikt zwischen fiskalischer Flexibilität und Glaubwürdigkeit: Ein Reform-ansatz unter Berücksichtigung konstitutionen- und institutionenökonomischer Aspekte, August 2003

Nr. 18: Ruehmann, Peter: Der deutsche Arbeitsmarkt: Fehlentwicklungen, Ursachen und Reformansätze, August 2003

Nr. 17: Suedekum, Jens: Subsidizing Education in the Economic Periphery: Another Pitfall of Regional Policies?, Januar 2003

Nr. 16: Graf Lambsdorff, Johann; Schinke, Michael: Non-Benevolent Central Banks, Dezember 2002

Nr. 15: Ziltener, Patrick: Wirtschaftliche Effekte des EU-Binnenmarktprogramms, November 2002

Nr. 14: Haufler, Andreas; Wooton, Ian: Regional Tax Coordination and Foreign Direct Investment, November 2001

Nr. 13: Schmidt, André: Non-Competition Factors in the European Competition Policy: The Necessity of Institutional Reforms, August 2001

Nr. 12: Lewis, Mervyn K.: Risk Management in Public Private Partnerships, Juni 2001

Nr. 11: Haaland, Jan I.; Wooton, Ian: Multinational Firms: Easy Come, Easy Go?, Mai 2001

Nr. 10: Wilkens, Ingrid: Flexibilisierung der Arbeit in den Niederlanden: Die Entwicklung atypischer Beschäftigung unter Berücksichtigung der Frauenerwerbstätigkeit, Januar 2001

Nr. 9: Graf Lambsdorff, Johann: How Corruption in Government Affects Public Welfare - A Review of Theories, Januar 2001

Nr. 8: Angermüller, Niels-Olaf: Währungskrisenmodelle aus neuerer Sicht, Oktober 2000

Nr. 7: $\quad$ Nowak-Lehmann, Felicitas: Was there Endogenous Growth in Chile (1960-1998)? A Test of the AK model, Oktober 2000

Nr. 6: Lunn, John; Steen, Todd P.: The Heterogeneity of Self-Employment: The Example of Asians in the United States, Juli 2000

Nr. 5: Güßefeldt, Jörg; Streit, Clemens: Disparitäten regionalwirtschaftlicher Entwicklung in der EU, Mai 2000

Nr. 4: Haufler, Andreas: Corporate Taxation, Profit Shifting, and the Efficiency of Public Input Provision, 1999

Nr. 3: Rühmann, Peter: European Monetary Union and National Labour Markets, September 1999

Nr. 2: Jarchow, Hans-Joachim: Eine offene Volkswirtschaft unter Berücksichtigung des Aktienmarktes, 1999

Nr. 1: Padoa-Schioppa, Tommaso: Reflections on the Globalization and the Europeanization of the Economy, Juni 1999

Alle bisher erschienenen Diskussionspapiere zum Download finden Sie im Internet unter: http://www.uni-goettingen.de/de/60920.html. 